\title{
Nonpathogenic Isolates of the Citrus Black Spot Fungus, Guignardia citricarpa, Identified as a Cosmopolitan Endophyte of Woody Plants, G. mangiferae (Phyllosticta capitalensis)
}

\author{
R. P. Baayen, P. J. M. Bonants, G. Verkley, G. C. Carroll, H. A. van der Aa, M. de Weerdt, I. R. van Brouwershaven, \\ G. C. Schutte, W. Maccheroni Jr., C. Glienke de Blanco, and J. L. Azevedo
}

First and seventh authors: Plant Protection Service, P.O. Box 9102, 6700 HC Wageningen, the Netherlands; second and sixth authors: BioInteractions and Plant Health Unit, Plant Research International, P.O. Box 26, 6700 AA Wageningen, the Netherlands; third and fifth authors: Centraalbureau voor Schimmelcultures, P.O. Box 85167, 3508 AD Utrecht, the Netherlands; fourth author: Department of Biology, 1210 University of Oregon, Eugene; eighth author: Outspan Citrus Centre, P.O. Box 28, Nelspruit 1200, South Africa; tenth author: Department of Genetics, Universidade Federal do Paraná, Curitiba 81531-990, PR, Brazil; and ninth and eleventh authors: Department of Genetics, Escola Superior de Agricultura “Luiz de Queiroz,” Universidade de São Paulo, Piricicaba 13400-970, SP, Brazil. Accepted for publication 5 December 2001.

\begin{abstract}
Baayen, R. P., Bonants, P. J. M., Verkley, G., Carroll, G. C., van der Aa, H. A., de Weerdt, M., van Brouwershaven, I. R., Schutte, G. C., Maccheroni, W., Jr., Glienke de Blanco, C., and Azevedo, J. L. 2002. Nonpathogenic isolates of the citrus black spot fungus, Guignardia citricarpa, identified as a cosmopolitan endophyte of woody plants, $G$. mangiferae (Phyllosticta capitalensis). Phytopathology 92:464-477.

The population structure of Guignardia citricarpa sensu lato (anamorph: Phyllosticta citricarpa), a fungus of which strains pathogenic to citrus are subject to phytosanitary legislation in the European Union and the United States, was investigated. Internal transcribed spacer sequences revealed two phylogenetically distinct groups in $G$. citricarpa. This distinction was supported by amplified fragment length polymorphism analysis that also supported the exclusion of two isolates that had apparently been misclassified as G. citricarpa. On cherry decoction agar, but not on other media, growth rates of group I isolates were lower than those of group II isolates. Conidial dimensions were similar, but group I isolates formed conidia with barely visible mucoid sheaths, whereas those of group II formed conidia with thick sheaths. Cultures of isolates

belonging to group I produced rare infertile perithecia, whereas fertile perithecia were formed by most isolates of group II. Colonies of isolates belonging to group I were less dark than those of group II, with a wider translucent outer zone and a lobate rather than entire margin. On oatmeal agar, exclusively group I isolates formed a yellow pigment. Group I harbored strains from citrus fruits with classical black spot lesions (1 to $10 \mathrm{~mm}$ in diameter) usually containing pycnidia. Group II harbored endophytic strains from a wide range of host species, as well as strains from symptomless citrus fruits or fruits with minute spots $(<2-\mathrm{mm}$ diameter) without pycnidia. These observations support the historic distinction between slowly growing pathogenic isolates and morphologically similar fast-growing, nonpathogenic isolates of G. citricarpa. The latter proved to belong to $G$. mangiferae ( $P$. capitalensis), a ubiquitous endophyte of woody plants with numerous probable synonyms including $G$. endophyllicola, G. psidii, $P$. anacardiacearum, and $P$. theacearum. G. mangiferae occurs in the European Union and the United States on many host species including citrus, and does not cause symptoms of citrus black spot, justifying its exclusion from quarantine measures.
\end{abstract}

Citrus black spot, caused by Guignardia citricarpa Kiely sensu lato, is a fruit disease that affects the rind of Citrus fruit but does not cause internal decay $(9-12,30,32,33)$. Heavy infection near the pedicel of the developing fruit may lead to premature fruit drop. Losses may be substantial because affected fruits are no longer suited for the fresh fruit market, and yield losses and costs for chemical control can be significant $(11,32)$.

Benson (2) first reported black spot in citrus orchards near Sydney, Australia, and shortly after McAlpine described the causal agent as Phoma citricarpa McAlpine (14). The teleomorph, $G$. citricarpa Kiely was described in 1948 (9). The anamorph was later reclassified as Phyllosticta citricarpa (McAlpine) van der Aa (36). The spermatial state is in Leptodothiorella (36); however, the synanamorph has not been formally described.

The disease cycle was originally described from Australia by Kiely $(9,10)$, and was subsequently studied in southern Africa

Corresponding author: R. P. Baayen; E-mail address: r.p.baayen@pd.agro.nl

Publication no. P-2002-0227-01R

This article is in the public domain and not copyrightable. It may be freely reprinted with customary crediting of the source. The American Phytopathological Society, 2002.
$(11,17,18,22,23)$, where the disease had been introduced with bud wood imported from Australia (5) and had developed to epidemic levels. Perithecia develop on fallen infected leaves on the orchard floor, and from these, ascospores are released that serve as primary inoculum of leaves and fruits. After a period of latency, leaf spots and pycnidia develop on the infected leaves, and various lesion types (hard spot, virulent spot, freckle spot, and false melanose), and often pycnidia, develop on infected fruits $(9,10,12,32)$. Symptom development on mature fruit is enhanced by high temperatures, high light intensity, drought, and poor vigor (12). After harvest, storage of fruits in the light at $20^{\circ} \mathrm{C}$ further promotes the formation of pycnidia in the lesions (3). The role of pycnidia in the disease cycle is not clear. Attempts to inoculate plants with conidia have failed so far, suggesting that the ascospores are the prime source of infection $(12,17,22)$. Perithecia do not develop on leaves or fruits still on the tree, or on harvested fruits, but only on fallen and already decaying infected leaves (12). Ascospore production and host infection require warm and moist conditions (12). Indeed, the disease has thus far only been found in subtropical regions of the world that are subject to summer rainfall such as Argentina, eastern Australia, Brazil, China, Hong Kong, Indonesia, Japan, Kenya, Mozambique, Nigeria, Peru, Philippines, northeastern South Africa, Swaziland, Taiwan, Uruguay, Vene- 
zuela, and Zimbabwe $(8,12,31,34)$. Black spot is unknown in the citrus-producing countries or regions subjected to winter rainfall such as Chile, Greece, Israel, Italy, Spain, Turkey, the Cape Province of South Africa, and California.

Kiely (9) found that the fungus not only occurs on Citrus spp., but also on the leaves of various native Australian species growing near citrus groves (e.g., Telopea speciosissima) and on garden plants. On some of these plants, especially on the old leaves, restricted lesions up to $2 \mathrm{~mm}$ in diameter sometimes developed. Kiely concluded that such infections serve as a reservoir for the black spot fungus (9). In contrast, McOnie (16,19-21) did not find any evidence that any plant besides citrus plays a role in the epidemiology of the black spot disease. In the South African Cape Province, the fungus is commonly present in indigenous plants as well as in Citrus spp. (38), in line with the observations of Kiely (9). However, black spot symptoms did not occur in the Cape at all. Upon a closer scrutiny, isolates from the Cape Province differed in behavior from regular isolates from fruits with black spot symptoms; they grew faster, easily produced perithecia on culture media (whereas black spot-associated isolates remained sterile), and rarely produced pycnidia on culture media (whereas black spot-associated isolates produced pycnidia abundantly) (16). Subsequent inoculation trials revealed that the isolates from the Cape, although morphologically identical to G. citricarpa from black spot-affected fruits, were consistently nonpathogenic to oranges and grapefruits in infection trials (16,20). McOnie (16) concluded that Citrus and many other host species might harbor a latent Guignardia sp. that is morphologically similar to, but pathogenically different from, G. citricarpa. Well before McOnie's classical studies, Chiu (4) had reported the same two types of strains from Taiwan as well as their apparent association with the presence (absence) of black spot symptoms. Lee (13) subsequently demonstrated that Taiwanese isolates of the first group (those growing slowly and having a lobed margin) caused freckle and virulent spot on Ponkan fruit (Citrus tankan), whereas those of the second group (those growing rapidly and having an entire margin) penetrated the fruits but did not induce any black spot. The distinction between slowly growing pathogenic G. citricarpa and fast-growing nonpathogenic Guignardia sp. (also referred to as nonpathogenic strains of $G$. citricarpa) has been followed widely $(8,12,32)$. The host range of the nonpathogenic Guignardia sp. currently includes a wide array of families of wild and cultivated plants $(8,32,34)$. Its geographic distribution is much wider than that of pathogenic $G$. citricarpa, including important black spotfree citrus regions such as Florida, Spain, Sicily, and Israel (20,32).

The European Union and the United States consider pathogenic strains of G. citricarpa a serious phytosanitary risk and have regulated the import of fruit consignments. Consignments with black spot symptoms are refused. Quarantine legislation in the European Union is restricted to pathogenic strains of G. citricarpa (1) in order to exclude strains of the nonpathogenic Guignardia sp. reported by McOnie (16). Recent interceptions of black spotinfected fruit consignments have shown that the distinction is not very practicable. Black spot is traditionally diagnosed from classical fruit symptoms such as hard spot lesions containing pycnidia of $P$. citricarpa. The diagnosis becomes troublesome when no pycnidia are present in the lesions, which is often the case when only freckle spot or false melanose symptoms are found. In contrast to hard spot and virulent spot, freckle spot and false melanose are not very distinctive and can be easily confused with symptoms of other Citrus diseases such as true melanose (caused by Diaporthe citri), greasy spot (caused by Mycosphaerella citri), or lesions caused by Colletotrichum spp. (12). Such indistinct symptoms are commonly seen at import inspection. Culturing of the fungus is then required to verify that $G$. citricarpa is associated with the lesions, and that the fungus is a strain pathogenic to citrus. However, the fungus is difficult to culture because of competition with common endophytic fungi of citrus fruit such as Colletotrichum spp., and subtle differences in cultural characteristics require the study of pure cultures. Given the slow growth of the fungus (the formation of mature pycnidia may require 14 days) and the rapidly decreasing value of consignments held for quarantine testing, culturing is highly impracticable. Moreover, isolates in the authors' collections seemed to represent a continuum between the two groups described by McOnie (16), thus raising doubts about the validity of their distinction. The present study was undertaken to investigate whether the distinction is justified and at what level, and if so, whether more robust methods (morphological, cultural, or molecular) could be developed for differentiating pathogenic G. citricarpa from nonpathogenic Guignardia sp. during quarantine diagnosis.

\section{MATERIALS AND METHODS}

Fungal strains. Investigated isolates of $G$. citricarpa sensu lato from Citrus spp. and from associated host species are listed in Table 1. Reference isolates of Guignardia and Phyllosticta spp. are listed in Table 2.

DNA extraction, amplification, and sequencing. Strains were grown in potato dextrose broth (Difco Laboratories, Detroit) at room temperature for 3 weeks, after which the mycelium was harvested, freeze-dried, and ground (10 to $50 \mathrm{mg}$ ) in microcentrifuge tubes with sterile sand and a pestle. DNA was isolated using the Puregene kit (Gentra/Biozym, Landgraaf, the Netherlands) according to the instructions of the manufacturer. Internal transcribed spacer-polymerase chain reaction (ITS-PCR) was performed with primers ITS1 (5' TCCGTAGGTGAACCTGCGG) and ITS4 (5' TCCTCCGCTTATTGATATGC) as described by White et al. (41). Cycle sequencing of PCR products was performed according to Werres et al. (40). PCR products (550 bp) were sequenced on an automatic sequencer (AB13700; Perkin-Elmer, Nieuwerkerk a/d IJssel, the Netherlands). Sequences were aligned, and phylograms were constructed with the MEGALIGN module of the DNASTAR software (DNASTAR Inc., Madison, WI). Representative ITS1 and ITS2 sequences are deposited as GenBank Accession Nos. AY042907 to AY042934.

In a number of cases, DNA was isolated and sequenced according to an alternative method described by Winton et al. (42). PCR reaction mixtures were prepared with the following components: $30 \mu \mathrm{l}$ of betaine $(4 \mathrm{M}), 10 \mu \mathrm{l}$ of $\mathrm{MgCl}_{2}(25 \mathrm{mM}), 10 \mu \mathrm{l}$ of PCR buffer, $8 \mu \mathrm{l}$ of dNTP's $(2.5 \mathrm{mM}), 2.5 \mu \mathrm{l}$ of bovine serum albumin (10 mg/ml), $2.0 \mu \mathrm{l}$ of Taq polymerase, and $27.5 \mu \mathrm{l}$ of deionized water. The total volume $(90 \mu \mathrm{l})$ was divided into $9-\mu \mathrm{l}$ aliquots and to each was added $0.4 \mu \mathrm{l}$ of the forward primer $(10 \mu \mathrm{M}), 0.4 \mu \mathrm{l}$ of the reverse primer $(10 \mu \mathrm{M})$, and $0.2 \mu \mathrm{l}$ of genomic DNA. PCR reactions were carried out in a RapidCycler (Idaho Technology, Salt Lake City, UT) in capillary tubes according to the following program: hold: $94^{\circ}, 15 \mathrm{~s}$; cycle: denature $94^{\circ}, 1 \mathrm{~s}$; anneal $55^{\circ}, 3 \mathrm{~s}$; elongation, $72^{\circ}, 15 \mathrm{~s}$ (slope $2.0,39$ cycles); hold: $72^{\circ}, 1 \mathrm{~min}$. Following completion of the thermocycling program, a $1.5 \%$ agarose gel (electrophoresis grade) prepared with a narrow comb was loaded with $5 \mu \mathrm{l}$ of sample in $5 \mu \mathrm{l}$ of loading buffer (total volume $10 \mu \mathrm{l}$ ) and run in Tris-borate-EDTA buffer at $70 \mathrm{~V}$ for $30 \mathrm{~min}$ with a 200 bp standard in the far left lane. Following electrophoresis, the entire gel was stained with SYBAR Gold (Molecular Probes, Eugene, OR) at 1:10,000 dilution for $15 \mathrm{~min}$. The gel was viewed on a with blue light and an amber-colored filter. Sequencing was carried out on an automated sequencer using a dye terminator sequencing kit (ABI 377; Perkin-Elmer Applied Biosystems, Foster City, CA).

Amplified fragment length polymorphism analysis. DNA $(250 \mathrm{ng})$ was digested in a $50-\mu \mathrm{l}$ reaction volume with EcoRI (10 units) and $\mathrm{MspI}$ (10 units) for $5 \mathrm{~h}$ at $37^{\circ} \mathrm{C}$ in restriction ligation buffer $(10 \mathrm{mM}$ Tris/HAc at $\mathrm{pH} 7.5,10 \mathrm{mM} \mathrm{MgAc}$, $50 \mathrm{mM}$ KAc, $5 \mathrm{mM}$ dithiothreitol, and bovine serum albumin at 
$50 \mathrm{ng} / \mu \mathrm{l})$, and adapters were ligated overnight to the restriction fragments in $40 \mu \mathrm{l}$ of reaction product $(10 \mu \mathrm{l}$ for gel $)$ at 10 to $12^{\circ} \mathrm{C}$. Final concentrations were 2.4 units of T4 DNA ligase (Pharmacia, Uppsala, Sweden), $0.1 \mu \mathrm{M}$ EcoRI adapter (5' CTCGTAGACTGCGTACC/CATCTGACGCATGGTTAA 5'), $1.0 \mu \mathrm{M}$ MspI adapter (5' GACGATGAGTCCTGAT/CTACTCAGGACTAGC $5^{\prime}$ ), and $0.2 \mathrm{mM}$ ATP. Nonselective amplification was performed with $5 \mu \mathrm{l}$ of $10 \times$ diluted ligation product added to $20 \mu \mathrm{l}$ of buffer $(10 \mathrm{mM}$ Tris- $\mathrm{HCl}$ at $\mathrm{pH} 8.3,50 \mathrm{mM} \mathrm{KCl}$, and $1.5 \mathrm{mM}$ $\mathrm{MgCl}_{2}$ ) with $60 \mu \mathrm{M}$ dNTP, primers Eco00 (5' GACTGCGTA-
CCAATTC) and $M s p 00$ (5' GATGAGTCCTGATCGG) at $5 \mathrm{ng} / \mu \mathrm{l}$, and 1 unit of Taq DNA polymerase (Boehringer GmbH, Mannheim, Germany). Reactions were performed in a thermocycler (PTC200; MJ Research, Watertown, MA) programmed as follows: $2 \mathrm{~min}$ at $94^{\circ} \mathrm{C} ; 35$ cycles of $30 \mathrm{~s}$ at $94^{\circ} \mathrm{C}, 30 \mathrm{~s}$ at $56^{\circ} \mathrm{C}$, and $90 \mathrm{~s}$ at $72^{\circ} \mathrm{C}$; and final extension of $10 \mathrm{~min}$ at $72^{\circ} \mathrm{C}$ and cooling to $4^{\circ} \mathrm{C}$. Amplicons were checked on $1.0 \%$ agarose gels and visualized with ethidium bromide and UV illumination.

Selective PCR was performed on $5 \mu$ of $20 \times$ diluted amplicons in a $20-\mu$ final reaction volume of the buffer mentioned above but

TABLE 1. Characteristics and identity of isolates received as Guignardia citricarpa arranged according to internal transcribed spacer (ITS) group and host ${ }^{\mathrm{a}}$

\begin{tabular}{|c|c|c|c|c|c|c|c|c|c|c|}
\hline Host & $\begin{array}{c}\text { Isolate } \\
\text { no. }\end{array}$ & Other codes ${ }^{b}$ & Source & Symptoms & Origin & $\begin{array}{l}\text { ITS } \\
\text { group }\end{array}$ & $\begin{array}{l}\text { AFLP } \\
\text { type }\end{array}$ & $\begin{array}{l}\text { Colony } \\
\text { diameter }\end{array}$ & $\begin{array}{l}\text { Yellow } \\
\text { pigment }\end{array}$ & Identity \\
\hline \multicolumn{11}{|l|}{ ITS group I } \\
\hline \multicolumn{11}{|l|}{ Rutaceae } \\
\hline Citrus aurantium & 2 & CBS 828.97 & Fruit & BS & Brazil & 1 & 1 & 25 & Present & G. citricarpa \\
\hline Citrus aurantium & 37 & IMI 304799 & Fruit & Unknown & India & 1 & 1 & 26 & Present & G. citricarpa \\
\hline Citrus limettioides & 39 & PPRI 1568 & Fruit & BS; pycnidia present & South Africa & 1 & 1 & 27 & Present & G. citricarpa \\
\hline Citrus limon & 35 & PPRI 5029 & Fruit & BS; pycnidia present & South Africa & 1 & 1 & 29 & Present & G. citricarpa \\
\hline Citrus limon & 46 & PPRI 6526 & Fruit & BS; pycnidia present & Brazil & 1 & 1 & 24 & Present & G. citricarpa \\
\hline Citrus limon & 51 & $\ldots$ & Fruit & Unknown & South Africa & 1 & 1 & 31 & Present & G. citricarpa \\
\hline Citrus limon & 54 & PPRI 1569 & Fruit & BS; pycnidia present & Argentina & 1 & 1 & 33 & Present & G. citricarpa \\
\hline Citrus reticulata & 40 & PPRI 5278 & Leaf & BS; no pycnidia & South Africa & 1 & 1 & 27 & Absent & G. citricarpa \\
\hline Citrus reticulata & 41 & PPRI 5276 & Fruit & BS; pycnidia present & South Africa & 1 & 1 & 26 & Present & G. citricarpa \\
\hline Citrus reticulata & 56 & PPRI 5277 & Unknown & BS; pycnidia present & Zimbabwe & 1 & NT & 16 & Present & G. citricarpa \\
\hline Citrus sinensis & 3 & $\ldots$ & Fruit & $\mathrm{BS} ;$ no pycnidia & Brazil & 1 & 1 & 29 & Present & G. citricarpa \\
\hline Citrus sinensis & 4 & $\ldots$ & Fruit & BS; no pycnidia & Brazil & 1 & 1 & 29 & Present & G. citricarpa \\
\hline Citrus sinensis & 5 & $\ldots$ & Fruit & BS; pycnidia present & Brazil & 1 & 1 & 23 & Present & G. citricarpa \\
\hline Citrus sinensis & 6 & $\ldots$ & Fruit & BS; pycnidia present & Brazil & 1 & 1 & 29 & Present & G. citricarpa \\
\hline Citrus sinensis & 9 & $\ldots$ & Fruit & BS; no pycnidia & Brazil & 1 & 1 & 25 & Present & G. citricarpa \\
\hline Citrus sinensis & 22 & $\ldots$ & Fruit & BS; pycnidia present & South Africa & 1 & 1 & 30 & Present & G. citricarpa \\
\hline Citrus sinensis & 23 & $\ldots$ & Fruit & BS; pycnidia present & South Africa & 1 & 1 & 28 & Present & G. citricarpa \\
\hline Citrus sinensis & 24 & $\ldots$ & Fruit & BS; pycnidia present & South Africa & 1 & 1 & 28 & Present & G. citricarpa \\
\hline Citrus sinensis & 25 & $\ldots$ & Fruit & BS; pycnidia present & South Africa & 1 & 1 & 27 & Present & G. citricarpa \\
\hline Citrus sinensis & 26 & $\ldots$ & Fruit & BS; pycnidia present & South Africa & 1 & 1 & 28 & Present & G. citricarpa \\
\hline Citrus sinensis & 27 & $\ldots$ & Fruit & BS; pycnidia present & South Africa & 1 & 1 & 29 & Present & G. citricarpa \\
\hline Citrus sinensis & 28 & $\ldots$ & Fruit & BS; pycnidia present & South Africa & NT & NT & 20 & Present & G. citricarpa \\
\hline Citrus sinensis & 29 & $\ldots$ & Fruit & BS; pycnidia present & South Africa & 1 & 1 & 31 & Present & G. citricarpa \\
\hline Citrus sinensis & 45 & PPRI 5350 & Fruit & BS; pycnidia present & South Africa & 1 & 1 & 24 & Present & G. citricarpa \\
\hline Citrus sinensis & 55 & PPRI 6514 & Leaf & BS; no pycnidia & South Africa & 1 & 1 & 25 & Present & G. citricarpa \\
\hline Citrus sinensis & 59 & GCS JB2PSQ2 & Fruit & BS; pycnidia present & South Africa & 1 & 1 & 28 & Present & G. citricarpa \\
\hline Citrus sinensis & 62 & GCS RV3 & Fruit & BS; pycnidia present & South Africa & 1 & 1 & 28 & Present & G. citricarpa \\
\hline Citrus sinensis & 63 & GCS B10 & Fruit & BS; pycnidia present & South Africa & 1 & 1 & 28 & Present & G. citricarpa \\
\hline Citrus sinensis & 64 & GCS B0 & Fruit & BS; pycnidia present & South Africa & 1 & 1 & 29 & Present & G. citricarpa \\
\hline Citrus sinensis & 67 & GCS JBmonshR & Fruit & BS; pycnidia present & South Africa & 1 & 1 & 25 & Present & G. citricarpa \\
\hline Citrus sinensis & 68 & GCS FVZB1S5R & Fruit & BS; pycnidia present & South Africa & 1 & 1 & 25 & Present & G. citricarpa \\
\hline Citrus sinensis & 69 & GCS TLMensyR & Fruit & BS; pycnidia present & South Africa & 1 & 1 & 21 & Present & G. citricarpa \\
\hline Citrus sinensis & 70 & GCS TR & Fruit & BS; pycnidia present & South Africa & 1 & 1 & 27 & Present & G. citricarpa \\
\hline Citrus sinensis & 71 & GCS TS & Fruit & BS; pycnidia present & South Africa & 1 & 1 & 24 & Present & G. citricarpa \\
\hline Citrus sinensis & 72 & GCS JBFSR5 & Fruit & BS; pycnidia present & South Africa & 1 & 1 & 30 & Present & G. citricarpa \\
\hline Citrus sp. & 1 & CBS 111.20 & Fruit & $\mathrm{BS}$ & China $^{\mathrm{c}}$ & 1 & 1 & 20 & Present & G. citricarpa \\
\hline Citrus sp. & 7 & $\ldots$ & Fruit & BS; pycnidia present & Brazil & 1 & 1 & 24 & Present & G. citricarpa \\
\hline Citrus sp. & 8 & $\ldots$ & Fruit & BS; pycnidia present & Brazil & 1 & 1 & 29 & Present & G. citricarpa \\
\hline \multicolumn{11}{|l|}{ ITS group II } \\
\hline Mangifera indica & 89 & PD 21003195 & Leaf & Leaf spot & Ghana & 2 & NT & 46 & Absent & G. mangiferae \\
\hline $\begin{array}{l}\text { Rhus crenata } \\
\text { Araliaceae }\end{array}$ & 112 & GCC RHUCRE 1-2 & Leaf & Absent & South Africa & 2 & NT & 34 & Absent & G. mangiferae \\
\hline $\begin{array}{l}\text { Schefflera sp. } \\
\text { Celastraceae }\end{array}$ & 91 & GCC SCHEFSP 1-1 & Leaf & Absent & Costa Rica ${ }^{\mathrm{d}}$ & 2 & NT & 50 & Absent & G. mangiferae \\
\hline Putterlickia verrucosa & 92 & GCC PUTVER 1-1 & Leaf & Absent & South Africa & 2 & NT & 37 & $\begin{array}{l}\text { Absent } \\
\text { (continued }\end{array}$ & $\begin{array}{l}\text { G. mangiferae } \\
\text { d on next page) }\end{array}$ \\
\hline
\end{tabular}

$\bar{a}$ Colony diameters (millimeters) were measured after 7 days growth on cherry decoction agar (CHA). Production of yellow pigment was evaluated after 7 days growth on oatmeal agar (OA). The thickness of the mucoid conidial sheath was assessed from conidia from approximately 14-day-old CHA cultures. BS, citrus black spot; NT, not tested.

b ATCC, American Type Culture Collection, Rockville, MD; CBS, Centraalbureau voor Schimmelcultures, Utrecht, the Netherlands; DAR, Plant Pathology Herbarium (HERB-DAR), Orange, NSW, Australia; GCC, G. C. Carroll, Eugene, Oregon; GCS, G. C. Schutte, Nelspruit, South Africa; IMI, former International Mycological Institute, Egham, U.K.; MEP, M. E. Palm, Beltsville, MD; PD, Plant Protection Service, Wageningen, the Netherlands; and PPRI, Plant Protection Research Institute, Pretoria, South Africa.

${ }^{c}$ Intercepted in New South Wales, Australia, on citrus peel from China; isolated and identified by W. A. Birmingham in 1920.

d Intercepted in California by USDA-APHIS in 1999.

e New South Wales.

f Torres Strait Islands.

$\mathrm{g}$ This is fast-growing perithecia-producing isolate PC-1 of Wang and Tsai (39). 
with $200 \mu \mathrm{M}$ dNTP and $5 \mathrm{ng}$ of Cy5-labeled fluorescent Eco20 primer (5' GACTGCGTACCAATTCGC) and $30 \mathrm{ng}$ of $M s p 15$ primer (5' GATGAGTCCTGATCGGCA). Reactions were performed under the following conditions: 1 cycle of $30 \mathrm{~s}$ at $94^{\circ} \mathrm{C}, 30 \mathrm{~s}$ at $65^{\circ} \mathrm{C}$, and $60 \mathrm{~s}$ at $72^{\circ} \mathrm{C} ; 13$ cycles of $72^{\circ} \mathrm{C}$ (annealing temperature was lowered by $0.7^{\circ} \mathrm{C}$ during each cycle); followed by 23 cycles of $30 \mathrm{~s}$ at $94^{\circ} \mathrm{C}, 30 \mathrm{~s}$ at $56^{\circ} \mathrm{C}$, and $60 \mathrm{~s}$ at $72^{\circ} \mathrm{C}$; and a final extension of $10 \mathrm{~min}$ at $72^{\circ} \mathrm{C}$ and cooling to $4^{\circ} \mathrm{C}$. Products were run on an AFLexpress automatic sequencer (Amersham Pharmacia Biotech, Roosendaal, the Netherlands) with a 50-bp ladder (Amer- sham) as a reference. Amplified fragment length polymorphism (AFLP) patterns were analyzed qualitatively with Imagemaster 1D software (Amersham). Presence or absence of bands was converted to binary data and incorporated in the analysis. A similarity matrix was constructed according to the method of Nei and $\mathrm{Li}$ (25). Unweighted pair group method cluster analysis of binary data was performed with Treecon software (35) and a similarity dendrogram was constructed with a distance scale.

Growth rate, cultural characteristics, and morphology. Culture media were prepared according to Gams et al. (6). Colony

TABLE 1. (continued from preceding page)

\begin{tabular}{|c|c|c|c|c|c|c|c|c|c|c|}
\hline Host & $\begin{array}{l}\text { Isolate } \\
\text { no. }\end{array}$ & Other codes ${ }^{b}$ & Source & Symptoms & Origin & $\begin{array}{l}\text { ITS } \\
\text { group }\end{array}$ & $\begin{array}{l}\text { AFLP } \\
\text { type }\end{array}$ & $\begin{array}{l}\text { Colony } \\
\text { diameter }\end{array}$ & $\begin{array}{l}\text { Yellow } \\
\text { pigment }\end{array}$ & Identity \\
\hline \multicolumn{11}{|l|}{ Cornaceae } \\
\hline Curtisia dentata & 93 & GCC CURDEN 1-1 & Leaf & Absent & South Africa & 2 & NT & 39 & Absent & G. mangiferae \\
\hline \multicolumn{11}{|l|}{ Euphorbiaceae } \\
\hline \multicolumn{10}{|l|}{ Lecythidaceae } & G. mangiferae \\
\hline \multicolumn{11}{|l|}{ Meliaceae } \\
\hline \multicolumn{8}{|l|}{ Moraceae } & 32 & Absent & G. mangiferae \\
\hline \multicolumn{11}{|l|}{ Musaceae } \\
\hline \multicolumn{11}{|l|}{ Pittosporaceae } \\
\hline \multicolumn{11}{|l|}{ Rubiaceae } \\
\hline \multicolumn{11}{|l|}{ Rutaceae } \\
\hline Citrus aurantiifolia & 85 & PPRI 1562 & Unknown & Unknown & Brunei & 2 & NT & 42 & Absent & G. mangiferae \\
\hline Citrus jambhiri & 53 & DAR 66105a & Leaf & Leaf spot & Australia $^{\mathrm{f}}$ & 2 & 2 & 54 & Absent & G. mangiferae \\
\hline Citrus limon & 10 & $\ldots$ & Fruit & Minute spots; no pycnidia & South Africa & 2 & 2 & 32 & Absent & G. mangiferae \\
\hline Citrus limon & 11 & $\ldots$ & Fruit & Minute spots; no pycnidia & South Africa & 2 & 2 & 36 & Absent & G. mangiferae \\
\hline Citrus limon & 12 & $\ldots$ & Fruit & Minute spots; no pycnidia & Argentina & 2 & 2 & 55 & Absent & G. mangiferae \\
\hline Citrus limon & 13 & $\ldots$ & Fruit & Minute spots; no pycnidia & Argentina & 2 & 2 & 47 & Absent & G. mangiferae \\
\hline Citrus limon & 48 & ATCC 32757 ; PC- $1^{\mathrm{g}}$ & Leaf & Unknown & Taiwan & 2 & 2 & 57 & Absent & G. mangiferae \\
\hline Citrus paradisi & 14 & $\ldots$ & Fruit & Minute spots; no pycnidia & Florida & 2 & 2 & 51 & Absent & G. mangiferae \\
\hline Citrus paradisi & 15 & $\ldots$ & Fruit & Minute spots; no pycnidia & Florida & 2 & 2 & 55 & Absent & G. mangiferae \\
\hline Citrus paradisi & 16 & $\ldots$ & Fruit & Minute spots; no pycnidia & Florida & 2 & 2 & 53 & Absent & G. mangiferae \\
\hline Citrus paradisi & 17 & $\ldots$ & Fruit & Minute spots; no pycnidia & Florida & 2 & 2 & 55 & Absent & G. mangiferae \\
\hline Citrus paradisi & 18 & $\ldots$ & Fruit & Minute spots; no pycnidia & Florida & 2 & 2 & 52 & Absent & G. mangiferae \\
\hline Citrus paradisi & 19 & M.E.P. 1445 & Fruit & Minute spots; no pycnidia & Florida & 2 & 2 & 50 & Absent & G. mangiferae \\
\hline Citrus paradisi & 20 & M.E.P. 1446 & Fruit & Symptomless peel & Florida & 2 & 2 & 54 & Absent & G. mangiferae \\
\hline Citrus paradisi & 21 & M.E.P. 1447 & Fruit & Symptomless peel & Florida & 2 & 2 & 45 & Absent & G. mangiferae \\
\hline Citrus paradisi & 73 & $\ldots$ & Fruit & Minute spots; no pycnidia & Florida & 2 & 2 & 59 & Absent & G. mangiferae \\
\hline Citrus reticulata & 36 & JW738E2 & Fruit & Unknown & Hong Kong & NT & NT & 57 & Absent & G. mangiferae \\
\hline Citrus reticulata & 86 & PPRI 1563 & Unknown & Unknown & Hong Kong & 2 & NT & 18 & Absent & G. mangiferae \\
\hline Citrus reticulata & 87 & PPRI 1565 & Unknown & Unknown & Hong Kong & 2 & NT & 45 & Absent & G. mangiferae \\
\hline Citrus sinensis & 47 & PPRI 1572 & Fruit & Unknown & Brazil & 2 & 2 & 45 & Absent & G. mangiferae \\
\hline $\begin{array}{l}\text { Citrus sp. } \\
\text { Zanthoxylum }\end{array}$ & 88 & PPRI 1567 & Fruit & Unknown & Japan & 2 & NT & 21 & Absent & G. mangiferae \\
\hline $\begin{array}{l}\text { martinence } \\
\text { Sapindaceae }\end{array}$ & 100 & GCC ZANMA 1-11 & Leaf & Absent & Puerto Rico & 2 & NT & 39 & Absent & G. mangiferae \\
\hline $\begin{array}{l}\text { Allophylus africanus } \\
\text { Smilacaceae }\end{array}$ & 101 & GCC ALLAF 1-1 & Leaf & Absent & South Africa & 2 & NT & 48 & Absent & G. mangiferae \\
\hline $\begin{array}{l}\text { Smilax kraussiana } \\
\text { Stangeriaceae }\end{array}$ & 90 & GCC SMIKRA 1-2 & Leaf & Absent & South Africa & 2 & NT & 39 & Absent & G. mangiferae \\
\hline $\begin{array}{l}\text { Stangeria eriopus } \\
\text { Theaceae }\end{array}$ & 102 & GCC STER 6-1 & Leaf & Absent & South Africa & 2 & NT & 38 & Absent & G. mangiferae \\
\hline $\begin{array}{l}\text { Camellia japonica } \\
\text { Viscaceae }\end{array}$ & 103 & GCC CAMJA 1-1 & Leaf & Absent & Louisiana & 2 & NT & 42 & Absent & G. mangiferae \\
\hline $\begin{array}{l}\text { Viscum obscurum } \\
\text { Vitaceae }\end{array}$ & 104 & GCC VISCOB 1-3 & Leaf & Absent & South Africa & 2 & NT & 16 & Absent & G. mangiferae \\
\hline $\begin{array}{l}\text { Rhoicissus tomentosa } \\
\text { Zamiaceae }\end{array}$ & 105 & GCC RHOTO 1-3 & Leaf & Absent & South Africa & 2 & NT & 33 & Absent & G. mangiferae \\
\hline Encephalartos ferox & 106 & GCC ENFE 3-2 & Leaf & Absent & South Africa & 2 & NT & 22 & Absent & G. mangiferae \\
\hline Encephalartos latifrons & 107 & GCC ENLAT 2-1 & Leaf & Absent & South Africa & 2 & NT & 30 & Absent & G. mangiferae \\
\hline Zamia integrifolia & 108 & GCC ZAMIN 1-2 & Leaf & Absent & Florida & 2 & NT & 47 & Absent & G. mangiferae \\
\hline $\begin{array}{l}\text { ITS group III } \\
\text { Proteaceae }\end{array}$ & & & & & & & & & & \\
\hline Telopea speciosissima & 52 & DAR 60749 & Leaf & Leaf spot & Australia $^{\mathrm{f}}$ & 3 & 4 & 58 & Absent & P. telopeae \\
\hline ITS group IV & & & & & & & & & & \\
\hline Unknown host & 38 & IMI 070028 & Unknown & Unknown & Japan & 4 & 3 & 16 & Absent & P. spinarum \\
\hline
\end{tabular}


diameters of strains were measured in duplicate after 7 days growth in darkness at $22^{\circ} \mathrm{C}$ on cherry decoction agar (CHA). For a subset of strains, additional single measurements were carried out after 7 days growth in darkness at $22^{\circ} \mathrm{C}$ on $\mathrm{CHA}$, malt extract agar (MEA), oatmeal agar (OA), and potato dextrose agar (PDA; Oxoid, London). Cultural characteristics were assessed, and the color of upper and lower sides of cultures was evaluated according to Rayner (28). Pigmentation was assessed after 7 days growth in darkness at $22^{\circ} \mathrm{C}$ on OA. For six slowly growing isolates and six fast-growing ones, the diameter of 10 pycnidia and the length and width of 30 conidia were determined from cultures that had been grown for 12 days in darkness at $22^{\circ} \mathrm{C}$ on $\mathrm{CHA}$, followed by 2 days under near-UV illumination $(8 \mathrm{~h}$ per $24 \mathrm{~h})$. The thickness of the mucoid conidial sheath was assessed from CHA cultures using differential interference contrast optics. Finally, a detailed morphological analysis including measurements of fungal organs and assessment of cultural morphology and color was made of the subset of slowly growing isolates $(35,37,46$, and 70$)$ and fastgrowing isolates $(12,19,36,44,48$, and 73) mentioned above after incubation at $18^{\circ} \mathrm{C}$, under $12 \mathrm{~h}$ near-UV light and $12 \mathrm{~h}$ darkness.

\section{RESULTS}

ITS sequence analysis. ITS sequence analysis revealed two major groups among the investigated isolates of $G$. citricarpa sensu lato (including isolates presumably belonging to nonpathogenic Guignardia sp. from citrus and associated host species) (Table 1; Figs. 1 and 2). Group I comprised 38 isolates from Citrus aurantium, C. limettioides, $C$. limon, $C$. reticulata, and $C$. sinensis from Argentina, Brazil, China, India, South Africa, and Zimbabwe. These isolates were obtained mainly from citrus fruits with classical black spot symptoms, generally including the presence of pycnidia in the lesions. Black spot symptoms varied from hard spot, often with a halo of freckle spot lesions, to virulent spot. Lesions were generally 2 to $10 \mathrm{~mm}$ in diameter, although satellite freckle spot lesions surrounding hard spot lesions tended to be smaller. Group I included isolate 1, a reference strain (CBS 111.20) of G. citricarpa. ITS1 sequences placed group I isolates close to $P$. hypoglossi and $P$. spinarum (Fig. 1). ITS2 sequences did not resolve their relationships to other species (Fig. 2).

Group II comprised 18 isolates from $C$. aurantiifolia, $C$. jambhiri, C. limon, C. paradisi, C. reticulata, and C. sinensis from Argentina, Australia, Brazil, Brunei, Hong Kong, Japan, South Africa, Taiwan, and the United States (Florida), an isolate from Zanthoxylum martinence (Rutaceae), and 21 isolates from 18 other host families (Table 1). Isolates from other host species generally originated from healthy leaves, where the fungus had been present endophytically, and coincidentally from spotted leaves. None of the isolates of this second group that came from Citrus spp. originated from fruits with classical black spot lesions and pycnidia; several had been obtained from leaves. When isolated from citrus fruits, these had been either completely free of symptoms, or had carried tiny $(<2 \mathrm{~mm}$, mostly $<1 \mathrm{~mm})$, somewhat atypical spots of uncertain origin, never associated with pycnidia. Two isolates were from healthy looking parts of grapefruits that had carried such atypical symptoms. ITS sequences of group II isolates were identical to those of $P$. capitalensis (Figs. 1 and 2). ITS1 sequences did not resolve their relationships to other species (Fig. 1). ITS2 sequences suggested that $P$. capitalensis and group II isolates are the sister group of G. philoprina (Fig. 2). Both ITS1 and ITS2 sequences placed groups I and II distant from each other, with 62 and 16 bp differences, respectively.

Group III consisted of a single isolate (isolate 52), received as G. citricarpa from Telopea speciosissima. Isolate 52 was reclassified as P. telopeae on basis of its large conidia (14.0 to $16.0 \times$ 8.9 to $10.6 \mu \mathrm{m})$, corresponding to the dimensions reported for $P$. telopeae (14 to $16.5 \times 8$ to $9.5 \mu \mathrm{m})(43)$ and well out of the range of those of $G$. citricarpa (6 to [ 9 to 10 ] to $13 \times 5$ to [ 6 to 7] to $9 \mu \mathrm{m}$ ) (36). ITS1 sequences placed isolate 52 close to G. aesculi, G. philoprina, and $P$. pyrolae (Fig. 1).

Group IV consisted of a single isolate (isolate 38) from an unknown host from Japan that had been received as G. citricarpa. Isolate 38 was reclassified as $P$. spinarum on basis of its ITS sequence.

ITS1 sequences grouped G. bidwellii and P. eugeniae together (Fig. 1). ITS1 and ITS2 sequences grouped $P$. hypoglossi and $P$. spinarum together (Figs. 1 and 2), and also $P$. owaniana and $P$. podocarpi. The reference strain of $P$. abietis clustered consistently at the root of the tree. Most other Guignardia and Phyllosticta spp. clustered inconsistently in both trees. The single isolate of Phoma epicoccina (=Epicoccum nigrum) clustered at the root of the tree.

AFLP grouping of isolates. AFLP patterns grouped a subset of 38 isolates in two main groups, corresponding with groups I and II resolved by ITS sequence analysis (Fig. 3). AFLP analysis supported the exclusion of isolates 38 ( $P$. spinarum) and $52(P$. telopeae).

Growth rates of cultures. Growth rates of cultures of $G$. citricarpa sensu lato formed a continuum (Table 1; Figs. 4 and 5). The average colony diameter of group I isolates on CHA after 7 days growth at $22^{\circ} \mathrm{C}$ in darkness ( 25 to $30 \mathrm{~mm}$ ) was lower than that of group II isolates $(\geq 40 \mathrm{~mm})$, both in the first experiment (Table 1; Fig. 4), and in the second, which comprised a subset of

TABLE 2. Investigated isolates of reference species of Guignardia, Phyllosticta, and Phoma used in this study

\begin{tabular}{|c|c|c|c|c|c|}
\hline Species & Isolate $^{\mathrm{a}}$ & Host & Source & Origin & Accession no. \\
\hline G. aesculi & CBS 756.70 & Aesculus hippocastanum & Leaf spot & Germany & AY042933, AY042934 \\
\hline G. bidwellii & CBS 237.48 & Parthenocissus tricuspidatus & Unknown & Unknown & AY042931, AY042932 \\
\hline G. philoprina & CBS 447.68 & Taxus baccata & Needle & The Netherlands & AF312014 \\
\hline \multicolumn{6}{|l|}{ Phoma epicoccina } \\
\hline (=Epicoccum nigrum) & CBS $873.72^{\mathrm{b}}$ & Artocarpus heterophylla & Leaf & India & AY042929, AY042930 \\
\hline Phyllosticta abietis & GCC ABCO 202 & Abies concolor & Symptomless leaf & California & AF312012 \\
\hline Phyllosticta beaumarisii & CBS $535.87(\mathrm{~T})$ & Muehlenbeckia adpressa & Leaf & Australia & AY042927, AY042928 \\
\hline \multirow[t]{2}{*}{ Phyllosticta capitalensis } & CBS 226.77 & Paphiopedilum callosum & Spotted leaves & Germany & AB041240 \\
\hline & CBS 398.80 & Orchid & Unknown & New Zealand (ex Singapore) & AB041241 \\
\hline Phyllosticta eugeniae & CBS 445.82 & Eugenia aromatica & Leaf & Indonesia & AY042925, AY042926 \\
\hline Phyllosticta hypoglossi & CBS 434.92 & Ruscus aculeatus & Dead cladodes & Italy & AY042923, AY042924 \\
\hline Phyllosticta owaniana & GCC s.n. & Brabejum stellatifolium & Leaf spot & South Africa & AF312011 \\
\hline Phyllosticta podocarpi & GCC POLA 3-6 & Podocarpus lanceolata & Symptomless leaf & South Africa & AF312013 \\
\hline Phyllosticta pyrolae & GCC s.n. & Pyrola asarifolia & Symptomless leaf & Oregon & AF312010 \\
\hline \multirow[t]{2}{*}{ Phyllosticta spinarum } & CBS 292.90 & Chamaecyparis pisifera & Unknown & France & AF312009 \\
\hline & CBS $937.70^{c}$ & Hedera helix & Leaf litter & Italy & AF312008 \\
\hline
\end{tabular}

a CBS, Centraalbureau voor Schimmelcultures, Utrecht, the Netherlands; GCC, collection of G. C. Carroll.

b Received as Phyllosticta artocarpina.

c Received as G. philoprina. 
the isolate collection (Table 3; Fig. 5). However, the range of growth rates of group I isolates (16- to 33-mm diameter in 7 days) fell within that of group II (16 to $59 \mathrm{~mm}$ ). Growth rate differences were not or at best weakly reflected on OA and MEA (Fig. 5), although a tendency similar to that on cherry agar was observed on PDA (Table 3).

Pycnidia and conidia. All isolates formed conidiomata, which began to develop after 8 days, and produced conidia. The single exception was isolate 1 (an isolate from 1924), which formed pycnidia but failed to produce conidia any longer (it still had done so in 1973) (34). Pycnidia were produced faster by isolates belonging to group I than by those of group II. Isolates belonging to groups I and II had similarly sized pycnidia and conidia (Table 3). Conidia of isolates of group I were 9.4 to (10 to 12) to $12.7 \times$ 5.0 to $(6.0$ to 7.5$)$ to $8.5 \mu \mathrm{m}$, whereas those of group II isolates were 9.7 to (11 to 12$)$ to $13.4 \times 6.1$ to $(6.5$ to 7.5$)$ to $7.5 \mu \mathrm{m}$. The thickness of the mucoid sheath surrounding the conidium wall differed independently of the medium. Group I isolates mainly formed conidia with barely visible sheaths, or sheaths no thicker than $1.5 \mu \mathrm{m}$, whereas those of group II formed conidia with very thick (1.5 to 2.5 (to 3 ) $\mu \mathrm{m}$ ) mucoid sheaths (Fig. 6). Group I isolates also tended to form longer apical appendages, but this feature was more variable among strains. Moreover, appendages that adhere to the surface of the glass or other material in water mounts may be stretched and their actual length overestimated.

The morphology of pycnidia, conidia, and spermatia of group II isolates (those not associated with black spot symptoms) was the following: conidiomata were globose, occasionally pyriform, 150 to $300 \times 100$ to $250 \mu \mathrm{m}$, with a single papillate ostiole, glabrous or with short irregular hyphal outgrowths on the surface, walls similar to those of the perithecia. Conidiogenous cells were discrete, rarely integrated, determinate, holoblastic, short-cylindrical to ampulliform, 8 to $15 \times 3.5$ to $5.5 \mu \mathrm{m}$. Conidia were ovoid to almost pyriform, more rarely ellipsoid, hyaline, whitish in mass, multiguttulate, 9 to $13.5 \times 6$ to $7.5 \mu \mathrm{m}$, truncate-rounded or truncate at the base, broadly rounded at the apex, with a flexible, 4 to 6 (to 10) $\mu \mathrm{m}$ long mucoid apical appendage, and the entire conidium wall surrounded by a stout, rigid 1.5 to 2.5 (to 3 ) $\mu$ m thick mucoid sheath. The spermatial state belonged to the form genus Leptodothiorella. Spermatiogenous cells were formed in the same or in

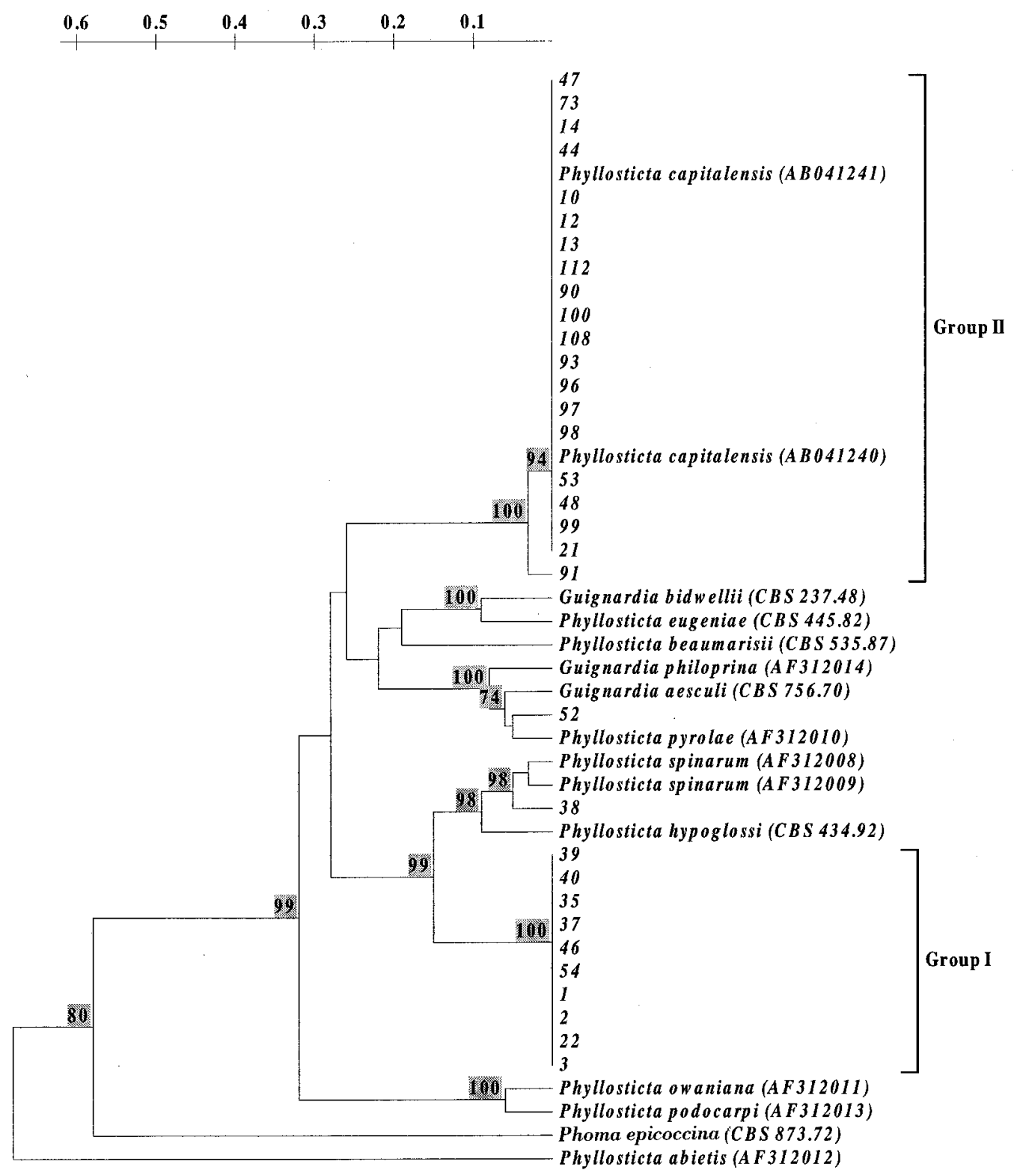

Fig. 1. Phylogram based on the internal transcribed spacer 1 region of the ribosomal DNA of 10 isolates of Guignardia citricarpa sensu lato group I (=G. citricarpa proper), 20 isolates of group II (=G. mangiferae), an isolate (38) later identified as Phyllosticta spinarum, an isolate (52) later identified as $P$. telopeae, and 15 isolates of reference species. Bootstrap values (1,000 replicates) are given above the nodes. 
separate conidiomata, discrete or integrated, cylindrical, 4.5 to $9.5 \times 1.0$ to $2.5 \mu \mathrm{m}$. Spermatia were dumbbell-shaped, mostly 7 to $10 \times 1.8$ to $2.5 \mu \mathrm{m}$, containing a few minute guttules.

Perithecia and ascospores. Cultures of isolates belonging to group I produced rare infertile perithecia and no ascospores. Fertile perithecia and ascospores were formed in most isolates of group II. On CHA, numerous perithecia started to develop after 2 weeks and sporulated within 4 weeks. Fewer fertile perithecia were formed on OA. On MEA, perithecia were also occasionally formed, but mature asci were never observed. Perithecia mostly developed above the agar surface, within brittle, black, columnar or irregularly pustulate elevations, mainly composed of interwoven hyphae and fruiting bodies, that were in part also conidiomata that produced conidia as well as spermatia. Perithecia were globose, pyriform, or almost cylindrical, black, 250 to $400 \times 175$ to $250 \mu \mathrm{m}$, with a single papillate to rostrate ostiole, the surface often covered with irregular hyphal outgrowths, the outer wall layer composed of angular cells with brown thickened walls, the inner layer of angular to globose cells with thinner colorless walls. Asci were fasciculate, bitunicate, clavate, eight-spored, the apex rounded, 65 to $100 \times 10$ to $14 \mu \mathrm{m}$ shortly before rupture of the outer wall (at maximum turgor), then cylindrical-clavate and extending in length to 120 to 135 (to 150) $\mu \mathrm{m}$ prior to dehiscence. Ascospores were short-cylindrical and swollen in the middle, slightly curved, 15 to $17.5 \times 6.5$ to $7.5 \mu \mathrm{m}$, heteropolar with unequal obtuse ends, the smaller upper end provided with a 1.0 to $2.0 \mu \mathrm{m}$ long truncate, noncellular, mucoid cap-like appendage, the lower end with a 3.0 to $6.0 \mu \mathrm{m}$ long acute or ruffled appendage, multiguttulate. No differences in details of ascospore morphology were apparent when the ascospores produced in culture by group II isolates were compared with published illustrations of ascospores of G. citricarpa from perithecia formed naturally in fallen leaves of black spot-infected citrus trees that supposedly represent group I (16).

Cultural characteristics. Cultural characteristics were studied in detail for four isolates of ITS group I (isolates 35, 37, 46, and 70) and six isolates of ITS group II (isolates 12, 19, 36, 44, 48, and 73). Colonies of isolates belonging to ITS group I were less dark than those of group II, with a much wider translucent outer zone, and a distinctly lobate rather than entire margin. On OA, all group I isolates produced a distinct yellow pigment, with the

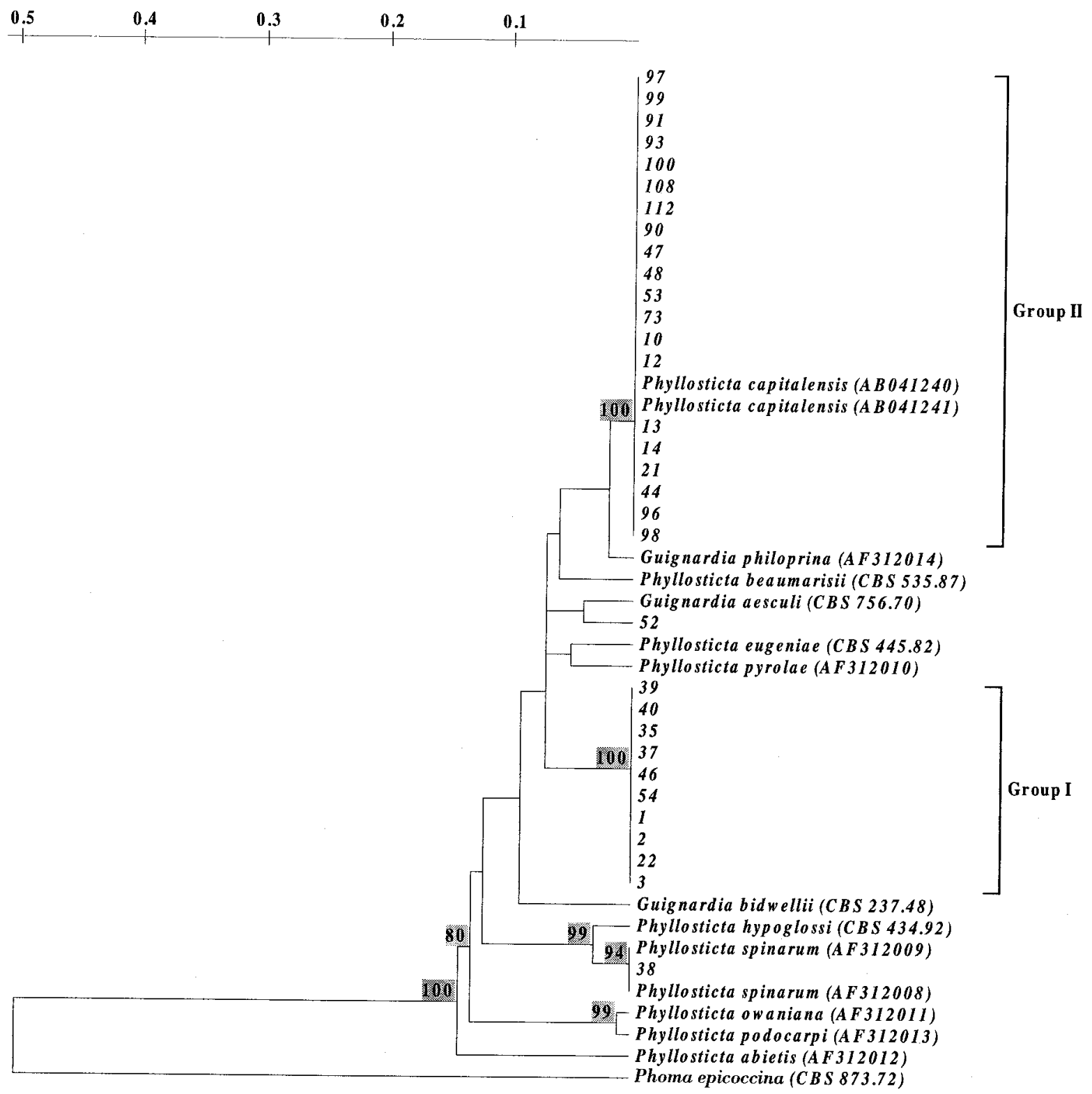

Fig. 2. Phylogram based on the internal transcribed spacer 2 region of the ribosomal DNA of 10 isolates of Guignardia citricarpa sensu lato group I (=G. citricarpa proper), 20 isolates of group II (=G. mangiferae), an isolate (38) later identified as Phyllosticta spinarum, an isolate (52) later identified as $P$. telopeae, and 15 isolates of reference species. Bootstrap values (1,000 replicates) are given above the nodes. 
exception of isolate 40, which failed to do so despite repeated tests (Table 1; Fig. 7). Colonies of isolates belonging to ITS group II were darker, with only a narrow translucent outer zone and a more entire margin. On OA, none of the group II isolates produced the yellow pigment (Table 1).

Group I isolates produced immersed mycelium on OA that was always first pure yellow to straw before becoming dark herbage green. On CHA, they grew much slower than isolates belonging to group II, with a somewhat more irregular margin, lined by a much wider translucent zone of colorless immersed mycelium, which was largely covered by pure white, but later often more sulphur yellow or primrose, felty to woolly-floccose aerial mycelium that often reached the margin. Only the center of the colony was much darker, and here the aerial mycelium was gray or glaucous, often with numerous small tufts. The colony reverse was only very dark in the center, surrounded by areas of grayish sepia and buff. On MEA, group I isolates again had a much wider, brighter-colored zone that was largely hidden under a dense layer of white, later often faintly yellowish (straw), appressed woolly aerial mycelium. In the center of the colony, well-developed glaucous gray to greenish gray aerial mycelium was found. Stromatal development in the center was less pronounced than in group II. The colony reverse was also with a much wider, first buff, later often pale luteous marginal zone.

Colonies of group II isolates on OA had an almost even or more irregular glabrous colorless margin. The surface of the colony was smooth, plane, and the immersed mycelium dull green or gray olivaceous, almost olivaceous black in the center. Aerial myceli- um formed only near the center, and was scanty, diffuse, woolly to woolly-floccose, grayish. The reverse was concolorous. Conidiomata began to develop after 8 days. On CHA, colonies had an even to slightly undulating, later mostly irregular, almost glabrous, colorless margin. The colony surface was iron gray or greenish gray after 8 days, to almost black after 14 days, except for a narrow translucent outer zone, plane, but already after 8 days with numerous black, semi-immersed globular conidiomata that were glabrous or bore gray aerial mycelial outgrowths. Soon afterwards, perithecia also started to develop and sporulate within 4 weeks. The aerial mycelium was well developed throughout, especially in the center of the colony, and was woolly-floccose, gray. The reverse was mostly dark slate blue. Colonies on MEA had a lobate or raffled margin, appearing as a narrow, glabrous and colorless zone, or whitish due to diffuse, appressed, white aerial mycelium; colonies appearing restricted after 8 days, with an irregular, bumpy glaucous gray or greenish gray surface, the central part with numerous semi-immersed to almost superficial single globular, to complex, black stromatal masses bearing grayish white aerial hyphae; aerial mycelium well developed over most of the colony, felty to short-tufty, mostly glaucous gray, but locally white. The reverse was olivaceous black or dark slate blue, but with a narrow buff zone at the margin.

\section{DISCUSSION}

The molecular and morphological data presented in this study show that ITS groups I and II of G. citricarpa sensu lato are

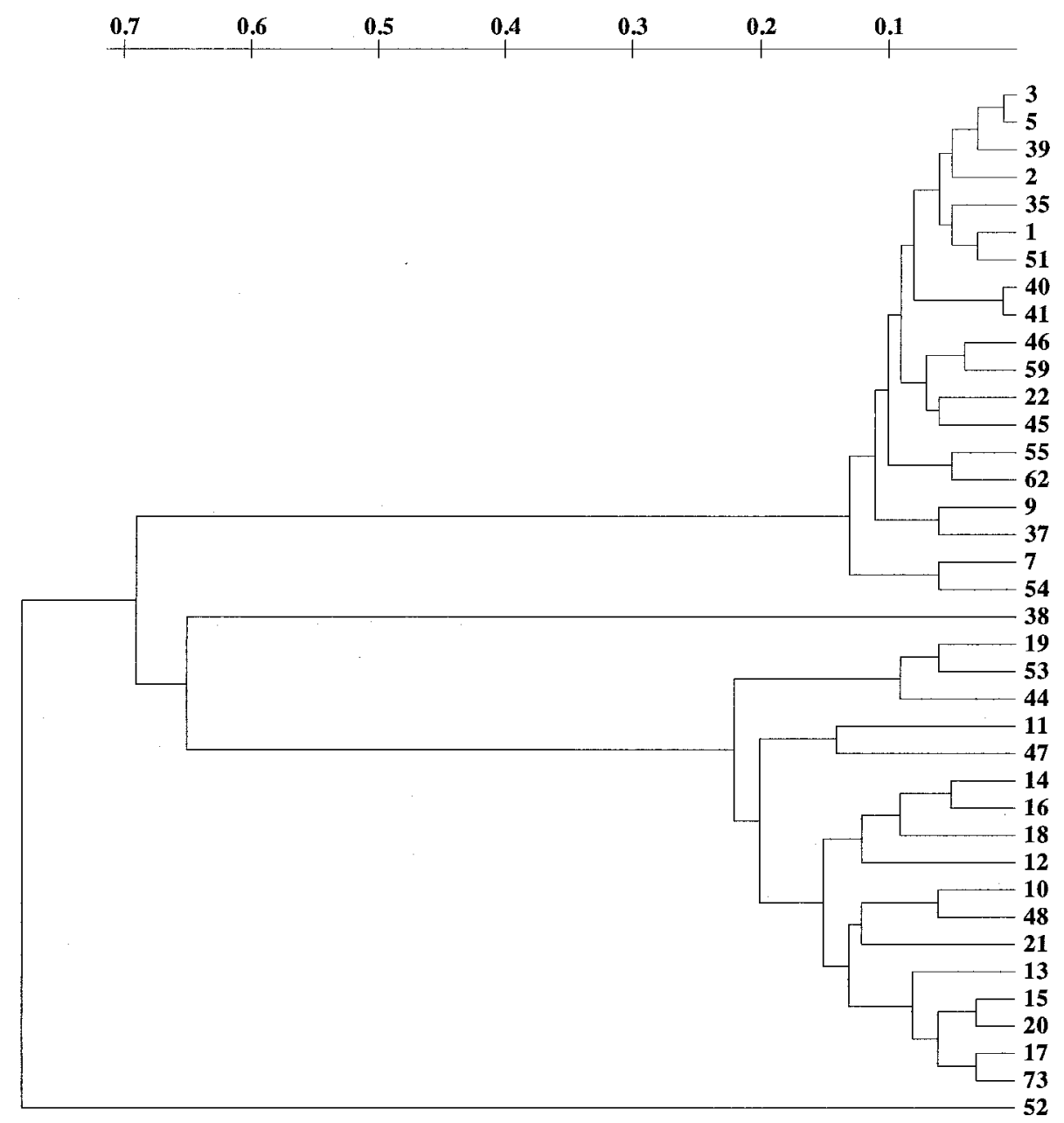

Fig. 3. Unweighted pair group method dendrogram constructed from amplified fragment length polymorphism fingerprint patterns of 19 isolates of Guignardia citricarpa sensu lato group I (=G. citricarpa proper), 17 isolates of group II (=G. mangiferae), an isolate (38) later identified as Phyllosticta spinarum, and an isolate (52) later identified as P. telopeae. 
distinct species. Further support for this assumption comes from variable intron sequences in genes for histone 4, translation elongation factor EF- $1 \alpha$, chitin synthase, calmodulin, and spermidine synthase (G. C. Carroll, unpublished data), and from random amplified polymorphic DNA data (G. Glienke de Blanco, unpublished data). Similar conclusions were recently reached by Meyer et al. (24). Group I comprised all isolates from black spot-affected citrus fruit, and corresponded to McOnie's group of strains pathogenic to citrus (16) in their slow growth and lack of perithecia in pure culture. We therefore conclude that these strains correspond to G. citricarpa proper. Group II isolates generally grew rapidly, easily produced perithecia and ascospores, were never associated with black spot symptoms, and originated from a range of host species, all in line with McOnie's (16) unnamed Guignardia sp. from citrus and associated hosts. Groups III and IV consisted of single, apparently misidentified, strains of $P$. telopeae and $P$. spinarum, respectively.

ITS sequence analysis identified group II as possibly conspecific with $P$. capitalensis, a species described from orchids (36). $P$. capitalensis was recently found to grow endophytically in Rhododendron and Enkianthus in Japan, and to produce a hitherto unknown teleomorph newly described as G. endophyllicola (26). The morphological descriptions of the anamorphic and teleomorphic states of the strains of $P$. capitalensis from Rhododendron, Enkianthus, and orchids investigated in the latter study (including present reference strains CBS 226.77 and CBS 398.80 from orchids) confirm that the isolates from Citrus spp. and other hosts presently placed in ITS group II belong to $P$. capitalensis.

Our data show that $P$. capitalensis occurs endophytically on a wide range of hosts belonging to numerous families. An overview of families and genera of host plants of $P$. capitalensis (identified by ITS sequences and species-specific primer pairs) is given in Table 4 . The recently reported endophytic occurrence of P. capitalensis in Ericaceae is therefore not surprising. The wide host range of $P$. capitalensis suggests that this fungus may have been described repeatedly from many different host species. Indeed, several older names in Phyllosticta and Guignardia probably are the same fungus. Based on the experience of one of the authors that nearly all isolates from members of the Anacardiaceae and Theaceae give sequences typical of $P$. capitalensis (G. C. Carroll, unpublished data), and given that the morphology of these isolates is grossly the same as that of $P$. capitalensis (present study; 36), we conclude that G. mangiferae (anamorph: P. anacardiacearum) and Guignardia sp. (anamorph: $P$. theacearum) are the same species as $G$. endophyllicola (anamorph: P. capitalensis). Isolates from spotted fruits of Psidium guajava with the morphology of $G$. citricarpa also corresponded to $P$. capitalensis in a molecular analysis (C. Glienke de Blanco and W. Maccheroni Jr., unpublished data), indicating that G. psidii is likely a synonym as well. Many more synonyms are likely to exist. In North America alone, some 600 Phyllosticta spp. have been described, and sequences from about 150 isolates from various localities worldwide have so far revealed no more than 30 phylogenetic species; about half of these isolates showed the same ITS sequence as $P$. capitalensis (G. C. Carroll, unpublished data).

A survey of the taxonomic literature on Phyllosticta and Guignardia spp. shows that the oldest names associated with isolates belonging to group II probably are $G$. mangiferae and $P$. capitalensis. P. capitalensis P. Hennings was described in 1908 (7). G. mangiferae A.J. Roy was described in 1968 (29). An older possible name, G. camelliae (Cooke) E.J. Butler, was described in 1884 from Camellia as Sphaerella (Laestadia) camilleae Cooke and was transferred to the genus Guignardia Viala \& Ravaz. after its establishment in 1892. However, the type material of G. camelliae proved to be Glomerella cingulata (Stoneman) Spauld. \& H. Schrenk (37), excluding the use of this name for the anamorph of $P$. theacearum. We, therefore, propose to designate isolates with the morphology and ITS sequence of group II as follows:

\section{Guignardia mangiferae A.J. Roy}

Guignardia mangiferae A.J. Roy, Indian Phytopathol. 20(1968):340-341.-G. endophyllicola I. Okane, A. Nakagiri \& T. Ito, Can. J. Bot. 79(2001):103.—G. psidii Ullasa \& Rawal, Curr. Sci. 53(1984):436. Anamorphic state: Phyllosticta capitalensis P. Hennings, Hedwigia 48(1908):13.-P. anacardiacearum Van der Aa, Stud. Mycol. 5(1973):31.-P. theacearum Van der Aa, Stud. Mycol. 5(1973):97. Spermatial state: Leptodothiorella sp.

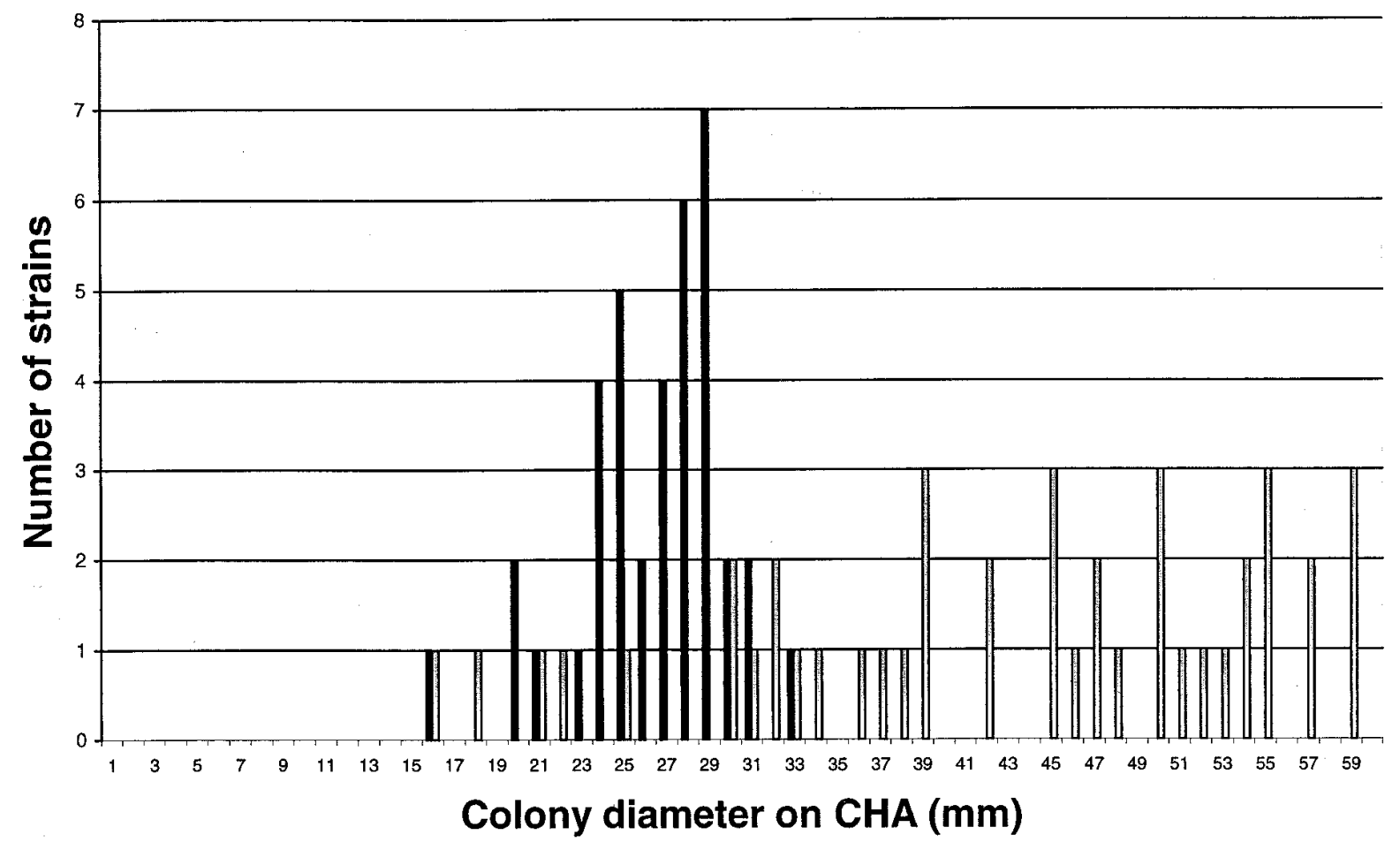

Fig. 4. Growth rate distribution of isolates of Guignardia citricarpa sensu lato group I (=G. citricarpa proper; black bars) and group II (=G. mangiferae; white bars) grown on cherry decoction agar (CHA). Colony diameters ( $x$ axis) were measured after 7 days growth in darkness at $22^{\circ} \mathrm{C}$. 
The present data confirm the reports by Chiu (4) and McOnie (16) that black spot is associated with slow growing Phyllosticta isolates, but not with the fast-growing ones that also form perithecia and ascospores in pure culture. Contrary to the main body of the black spot literature $(11,32)$, followed in the European Union legislation (1), the nonpathogenic isolates are not strains or physiologically specialized forms of G. citricarpa, but a separate species, G. mangiferae. Despite this, unambiguous morphological distinction of $G$. mangiferae from $G$. citricarpa is notoriously difficult. None of the characteristics given by Chiu (4) or McOnie (16) was found to separate both species unambiguously. Growth rates formed a continuum, even on CHA. Pycnidia were formed by all isolates, although slower by G. mangiferae than by G. citricarpa. Not all isolates of $G$. mangiferae formed fertile perithecia on agar, whereas, incidentally, isolates of G. citricarpa formed infertile ones. The margin of cultures of isolates of G. citricarpa is more distinctly lobed than that of cultures of most of the isolates of G. mangiferae, but exceptions to this rule exist and therefore individual isolates cannot be reliably identified on this criterion either. Altogether, the distinction made in quarantine legislation by the European Union and the United States, though scientifically justified, is nearly impossible to make in practice without molecular tools. The present study shows that the thickness of the mucoid sheath distinguishes $G$. mangiferae from $G$. citricarpa; however, the long period of time required for pycnidium formation makes this method unsuited for quarantine testing. The yellow pigment produced by $G$. citricarpa on $\mathrm{OA}$ is more useful, but even so sporulation is required because other fungi may resemble $G$. citricarpa while still sterile. The ITS sequences from this study have allowed us to produce a PCR method to test for the black spot fungus, which will be published in the near future.

The present study confirms previous reports that G. citricarpa, but not $G$. mangiferae, is associated with black spot symptoms. McOnie $(16,19,21)$ and Lee (13; and literature citation 39) have shown experimentally, through inoculation trials, that the socalled nonpathogenic strains (=G. mangiferae) do not cause black spot. This justifies the exclusion of such "nonpathogenic strains of
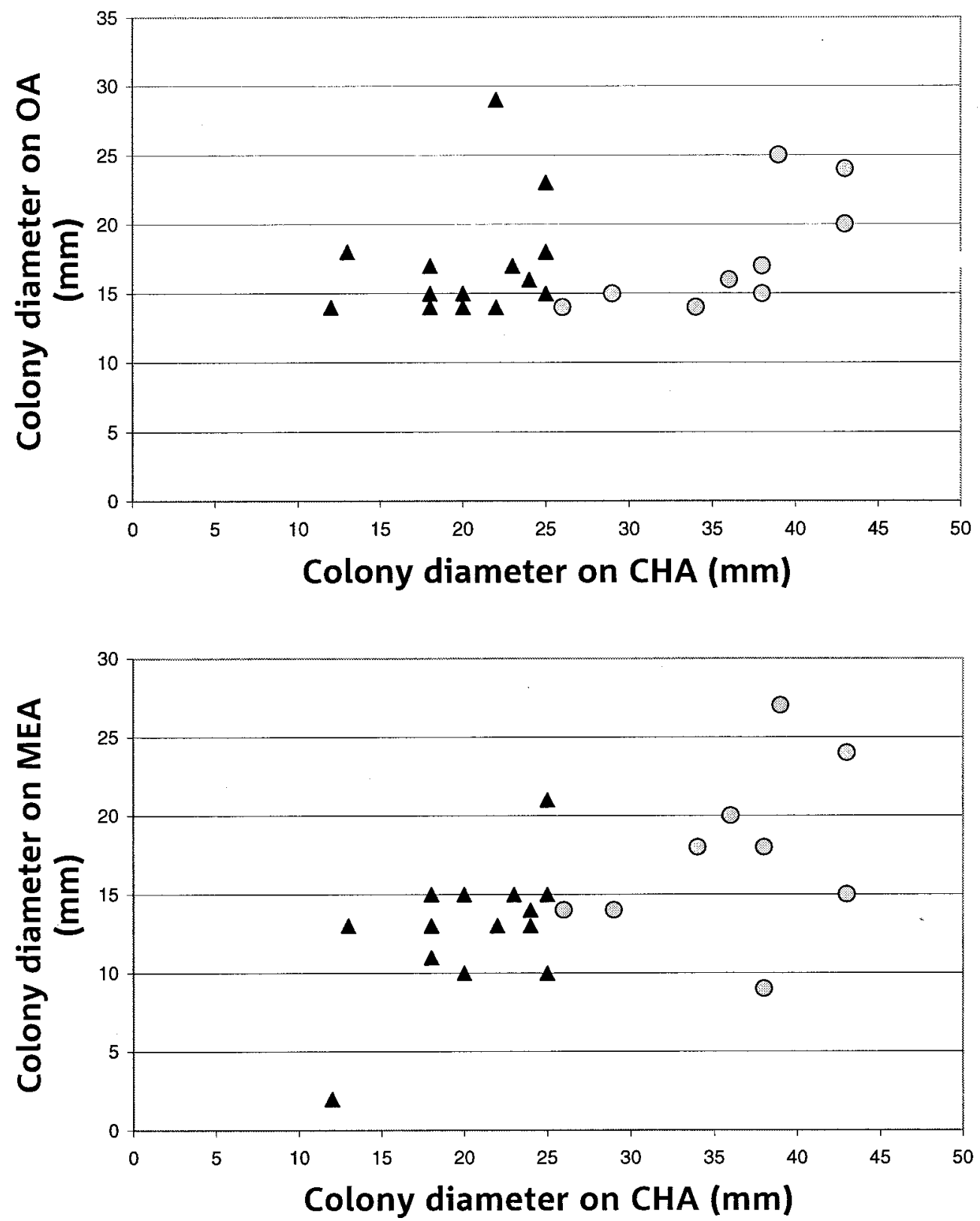

Fig. 5. Growth of 17 isolates of Guignardia citricarpa sensu lato group I (=G. citricarpa proper) (A) and nine isolates of group II (=G. mangiferae) (O) on cherry decoction agar (CHA), oatmeal agar (OA), and malt extract agar (MEA). Colony diameters were measured after 7 days growth in darkness at $22^{\circ} \mathrm{C}$. 
G. citricarpa" from quarantine legislation. Our data show that such strains belong to a cosmopolitan Guignardia (Phyllosticta) species that occurs on a wide range of woody plants, including Citrus spp., on all continents. The fungus is commonly present in Florida and also occurs in Europe, both on citrus and on orchids (and probably on more host species). Efforts to eradicate cosmopolitan G. mangiferae from citrus groves in regions in the European Union (Italy, Spain) and the United States (Florida) where this fungus occurs, but not G. citricarpa, will not serve any reasonable purpose. Similarly, preventing the introduction and spread of such strains when found on citrus fruit because of the precautionary principle is not scientifically justifiable nor is it necessary from a technical point of view because the two fungi can be identified unambiguously and rapidly through PCR.

The biology and ecology of $G$. mangiferae differ considerably from that of $G$. citricarpa. The latter species does not produce fertile perithecia on agar media although it does produce them on fallen leaves in the field (9), possibly indicative of heterothallism, whereas G. mangiferae is evidently homothallic. G. citricarpa readily produces spermatia, while $G$. mangiferae produces them only erratically (C. Glienke de Blanco and W. Maccheroni Jr., unpublished data). G. mangiferae is a ubiquitous, cosmopolitan

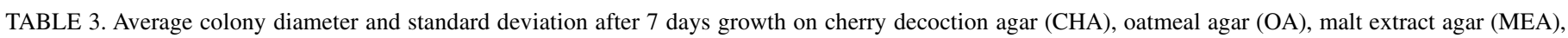

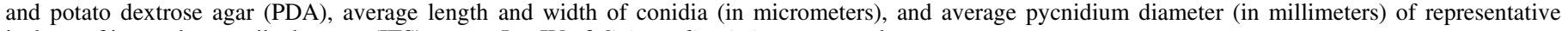
isolates of internal transcribed spacer (ITS) groups I to IV of Guignardia citricarpa sensu lato

\begin{tabular}{|c|c|c|c|c|c|c|c|}
\hline \multirow[b]{2}{*}{ ITS group and isolate no. } & \multicolumn{4}{|c|}{ Colony diameter (mm) } & \multicolumn{2}{|c|}{ Conidial dimensions } & \multirow{2}{*}{$\begin{array}{l}\text { Pycnidium } \\
\text { diameter }\end{array}$} \\
\hline & $\mathrm{CHA}$ & $\mathrm{OA}$ & MA & PDA & Length & Width & \\
\hline \multicolumn{8}{|l|}{ ITS group I (=G. citricarpa $)$} \\
\hline 1 & $15 \pm 1$ & $20 \pm 1$ & $28 \pm 4$ & $8 \pm 4$ & $9-10^{\mathrm{a}}$ & $6-7^{a}$ & $0.45 \pm 0.09$ \\
\hline 35 & $25 \pm 1$ & $17 \pm 1$ & $23 \pm 2$ & $22 \pm 4$ & $10.6 \pm 0.8$ & $7.5 \pm 0.6$ & $0.28 \pm 0.06$ \\
\hline 37 & $26 \pm 3$ & $14 \pm 1$ & $14 \pm 0$ & $28 \pm 5$ & $12.7 \pm 0.9$ & $8.5 \pm 0.8$ & $0.31 \pm 0.03$ \\
\hline 46 & $20 \pm 2$ & $19 \pm 1$ & $24 \pm 2$ & $13 \pm 4$ & $11.5 \pm 1.0$ & $8.2 \pm 0.6$ & $0.11 \pm 0.04$ \\
\hline 70 & $26 \pm 0$ & $22 \pm 1$ & $24 \pm 1$ & $25 \pm 0$ & $9.9 \pm 0.7$ & $6.9 \pm 0.5$ & $0.26 \pm 0.04$ \\
\hline \multicolumn{8}{|c|}{ ITS group II (=G. mangiferae) } \\
\hline 12 & $52 \pm 2$ & $27 \pm 3$ & $17 \pm 0$ & $32 \pm 4$ & $11.1 \pm 0.9$ & $7.0 \pm 0.7$ & $0.25 \pm 0.03$ \\
\hline 19 & $45 \pm 0$ & $29 \pm 2$ & $23 \pm 3$ & $35 \pm 3$ & $11.0 \pm 0.8$ & $7.4 \pm 0.5$ & $0.36 \pm 0.06$ \\
\hline 36 & $56 \pm 2$ & $17 \pm 1$ & $30 \pm 5$ & $35 \pm 4$ & $11.1 \pm 0.7$ & $7.4 \pm 0.5$ & $0.40 \pm 0.06$ \\
\hline 44 & $40 \pm 3$ & $31 \pm 1$ & $22 \pm 5$ & $30 \pm 1$ & $11.5 \pm 1.1$ & $7.5 \pm 0.7$ & $0.24 \pm 0.06$ \\
\hline 48 & $59 \pm 1$ & $23 \pm 4$ & $26 \pm 0$ & $44 \pm 1$ & $11.1 \pm 0.8$ & $6.5 \pm 0.5$ & $0.43 \pm 0.07$ \\
\hline 73 & $65 \pm 3$ & $30 \pm 2$ & $25 \pm 1$ & $45 \pm 3$ & $11.2 \pm 0.8$ & $7.1 \pm 0.6$ & $0.57 \pm 0.09$ \\
\hline \multicolumn{8}{|l|}{ ITS group III (=G. telopeae) } \\
\hline 52 & $50 \pm 4$ & $28 \pm 4$ & $34 \pm 2$ & $31 \pm 8$ & $15.2 \pm 1.1$ & $10.6 \pm 0.8$ & $0.50 \pm 0.7$ \\
\hline \multicolumn{8}{|c|}{ ITS group IV (=P. spinarum) } \\
\hline 38 & $16 \pm 4$ & $8 \pm 2$ & $10 \pm 1$ & $13 \pm 1$ & $10.9 \pm 2.2$ & $8.2 \pm 0.8$ & $\mathrm{NA}^{\mathrm{b}}$ \\
\hline
\end{tabular}

a Isolate 1 (=CBS 111.20) failed to produce conidia. Values for this isolate have been taken from a previous study (36).

b Not available: a few tiny pycnidia were produced in a single small dense cluster, which did not allow for measurement of individual pycnidial size.

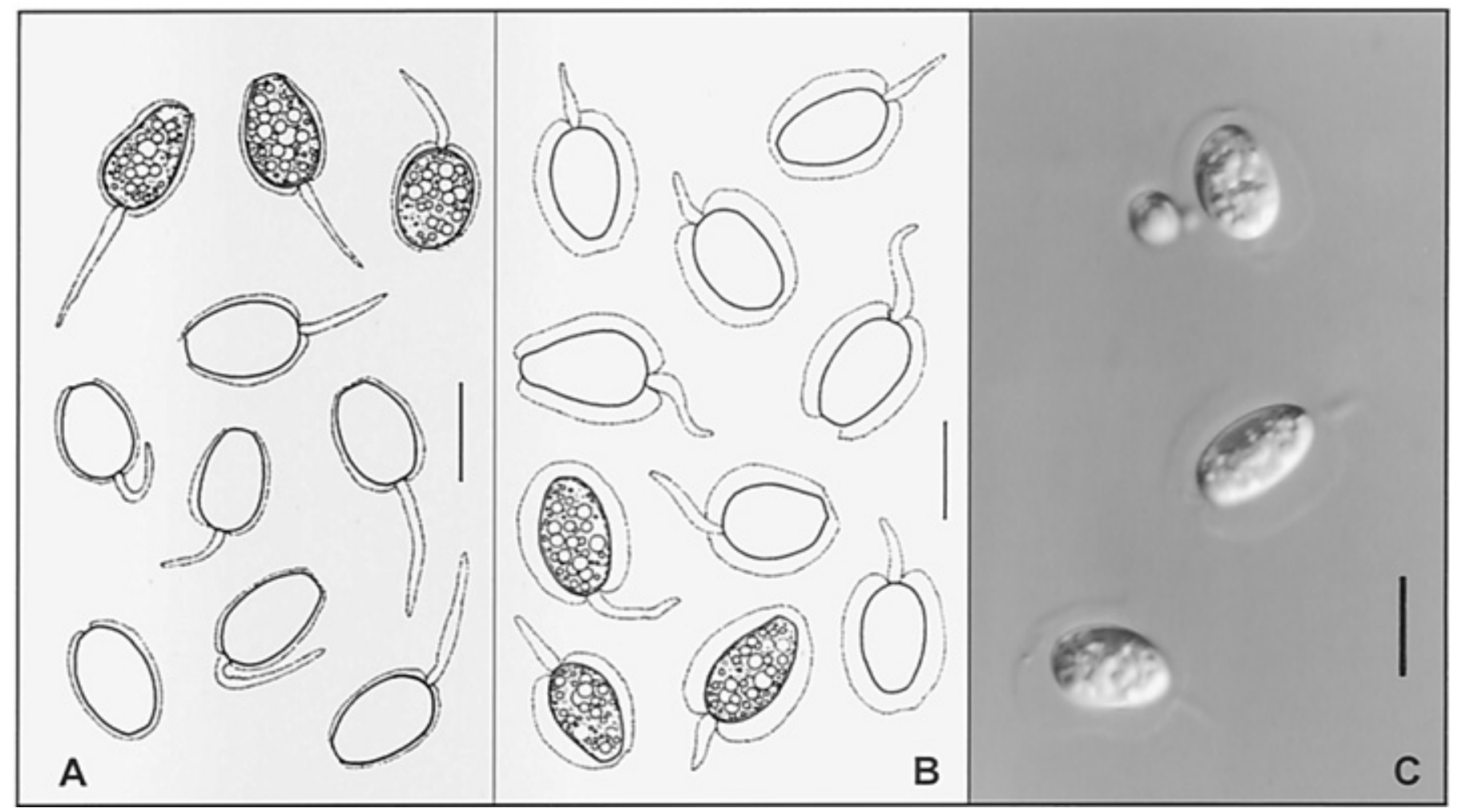

Fig. 6. Comparison of the mucoid conidial sheath of Guignardia citricarpa sensu lato group I (=G. citricarpa proper) and group II (=G. mangiferae). A, Camera lucida drawings of conidia of group I (isolate 70). B, Camera lucida drawings of conidia of group II (isolate 48). C, Photograph of conidia of group II (isolate 36). Scale bar $=10 \mu \mathrm{m}$. 


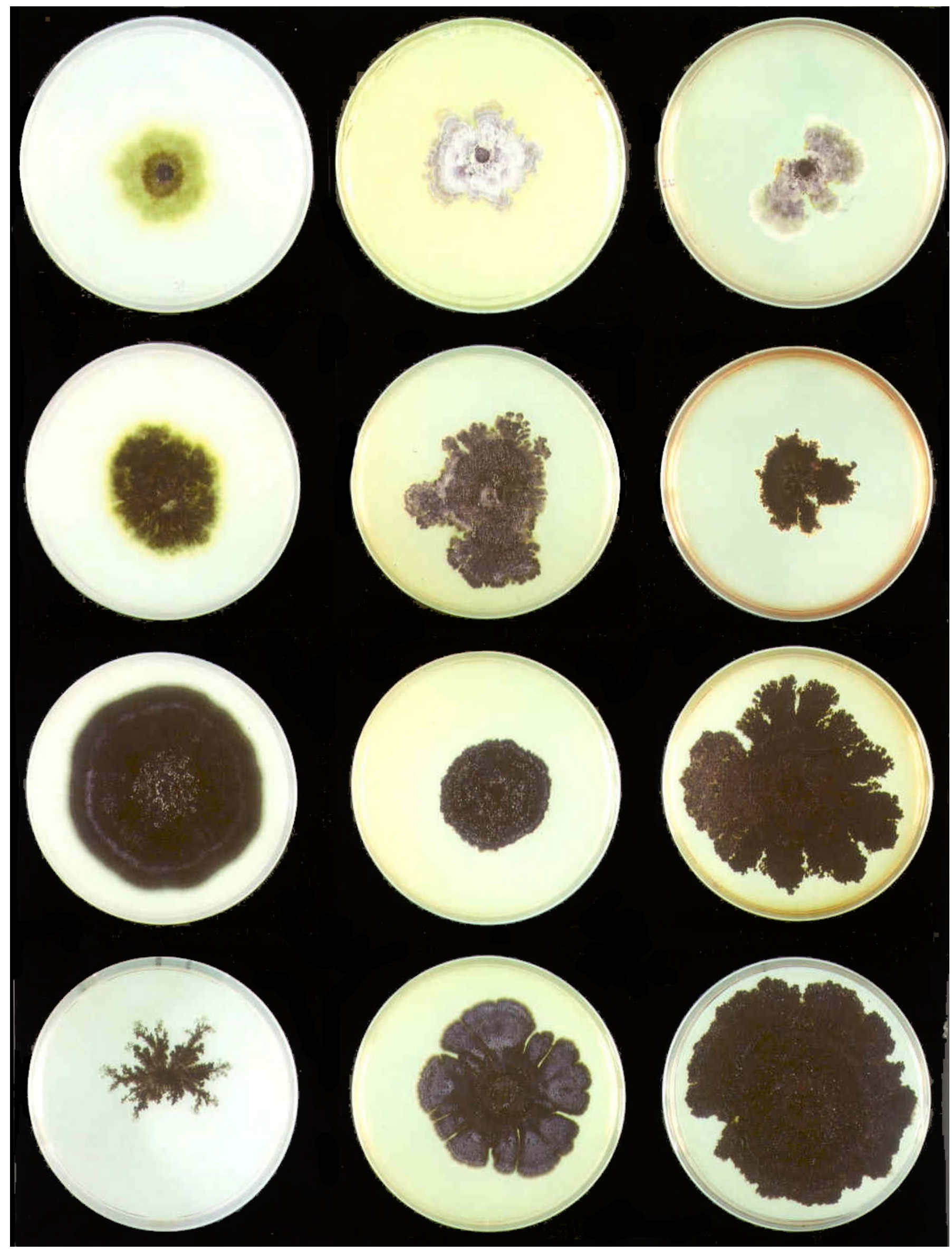

Fig. 7. Seven-day-old cultures of group I (=Guignardia citricarpa proper) isolates 1 and 37 (rows 1 and 2 ) and group II (=G. mangiferae) isolates 44 and 48 (rows 3 and 4). Left, oatmeal agar cultures; middle, malt extract agar cultures; and right, cherry decoction agar cultures. 
TABLE 4. Hosts infected endophytically with Guignardia mangiferae (Phyllosticta capitalensis), identified as such by molecular analysis

\begin{tabular}{|c|c|c|c|c|c|c|c|}
\hline Plant family & Host genus & Location & Source & Plant family & Host genus & Location & Source \\
\hline Acanthaceae & Mackaya & South Africa & G. C. Carroll ${ }^{\mathrm{a}}$ & Oleaceae & Schrebera & South Africa & G. C. Carroll ${ }^{\mathrm{b}}$ \\
\hline \multirow[t]{6}{*}{ Anacardiaceae } & Comocladia & Puerto Rico & G. C. Carroll ${ }^{\mathrm{a}}$ & Ophioglossaceae & Botrychium & Louisiana & G. C. Carroll ${ }^{\mathrm{a}}$ \\
\hline & Loxostylis & South Africa & G. C. Carroll ${ }^{\mathrm{a}}$ & Orchidaceae & Coelogyne & Thailand & G. C. Carroll ${ }^{\mathrm{a}}$ \\
\hline & & Ghana & Present study & & Paphiopedilum & Germany & Okane et al. (26) \\
\hline & Rhus & South Africa & Present study & Pittosporaceae & Pittosporum & Hawaii & Present study \\
\hline & Sclerocarya & South Africa & G. C. Carroll ${ }^{\mathrm{a}}$ & Podocarpaceae & Podocarpus & South Africa & G. C. Carroll ${ }^{\mathrm{a}}$ \\
\hline & Spondias & Brazil & G. C. Carroll ${ }^{\mathrm{a}}$ & Proteaceae & Leucospermum & Hawaii & G. C. Carrolla \\
\hline Aquifoliaceae & Ilex & Louisiana & G. C. Carroll ${ }^{\mathrm{a}}$ & Rhamnaceae & Scutia & South Africa & G. C. Carroll ${ }^{\mathrm{a}}$ \\
\hline \multirow[t]{4}{*}{ Araliaceae } & Cussonia & South Africa & G. C. Carroll ${ }^{\mathrm{a}}$ & & Zizyphus & South Africa & G. C. Carroll ${ }^{\mathrm{a}}$ \\
\hline & Hedera & South Africa & G. C. Carroll ${ }^{\mathrm{a}}$ & Rosaceae & Cliffortia & South Africa & G. C. Carroll ${ }^{\mathrm{a}}$ \\
\hline & Polyscias & Puerto Rico & G. C. Carroll ${ }^{\mathrm{a}}$ & Rubiaceae & Canthium & South Africa & G. C. Carroll ${ }^{\mathrm{b}}$ \\
\hline & Schefflera & Costa Rica & Present study & & Coprosma & Hawaii & Present study \\
\hline Boraginaceae & Cordia & South Africa & G. C. Carroll b & & Gardenia & South Africa & G. C. Carroll ${ }^{\mathrm{b}}$ \\
\hline Capparaceae & Maerua & South Africa & G. C. Carroll ${ }^{\mathrm{b}}$ & & Pavetta & South Africa & G. C. Carroll ${ }^{\mathrm{b}}$ \\
\hline \multirow[t]{2}{*}{ Ebenaceae } & $\begin{array}{l}\text { Diospyros } \\
\quad(3 \text { species })\end{array}$ & South Africa & G. C. Carroll ${ }^{\mathrm{a}}$ & & & $\begin{array}{l}\text { Africa, Taiwan, } \\
\text { Hong Kong, }\end{array}$ & study \\
\hline & Euclea (2 species) & South Africa & G. C. Carroll ${ }^{\mathrm{a}}$ & & & Mexico, Florida & \\
\hline \multirow[t]{2}{*}{ Ericaceae } & Enkianthus & Japan & Okane et al. (26) & & Fortunella & Louisiana & G. C. Carrolla \\
\hline & Rhododendron & Japan & Okane et al. (26) & & Vitex & South Africa & G. C. Carroll ${ }^{\mathrm{b}}$ \\
\hline \multirow[t]{3}{*}{ Euphorbiaceae } & Clutia & South Africa & Present study & & Zanthoxylum & Puerto Rico & Present study \\
\hline & Croton & South Africa & G. C. Carroll b & Sapindaceae & Allophylus & South Africa & G. C. Carroll ${ }^{\mathrm{a}}$ \\
\hline & Ctenomeria & South Africa & G. C. Carroll b & & Dodonaea & Hawaii & G. C. Carroll ${ }^{\mathrm{a}}$ \\
\hline Flacourtiaceae & Dovyalis & South Africa & G. C. Carroll ${ }^{\mathrm{b}}$ & & Litchi & South Africa & G. C. Carroll ${ }^{\mathrm{b}}$ \\
\hline Iteaceae & Itea & Louisiana & G. C. Carrolla & & Paullinia cupana & Brazil & C. Glienke de \\
\hline Lauraceae & Ocotea & South Africa & G. C. Carroll ${ }^{\mathrm{a}}$ & & & & Blanco $^{c}$ \\
\hline Lecythidaceae & Barringtonia & South Africa & Present study & Smilacaceae & Smilax & South Africa & Present study \\
\hline \multirow[t]{2}{*}{ Loganiaceae } & Strychnos & South Africa & G. C. Carroll ${ }^{\mathrm{a}}$ & Stangeriaceae & Stangeria & South Africa & Present study \\
\hline & Anthocleista & South Africa & G. C. Carroll b & Sterculiaceae & Sterculia & Puerto Rico & G. C. Carroll ${ }^{\mathrm{a}}$ \\
\hline & Psidium & Brazil & C. Glienke de & Zamiaceae & Encephalartos & South Africa & Present study \\
\hline & & & Blanco $^{c}$ & & Zamia & Florida & Present study \\
\hline
\end{tabular}

${ }^{a}$ Internal transcribed spacer sequence data.

${ }^{\mathrm{b}}$ Data obtained by using species-specific primer pairs.

${ }^{c}$ Unpublished random amplified polymorphism DNA data.

endophyte of woody plants, most of which seem to harbor the fungus without any visual symptoms. On mango $(15,27)$ and guava (C. Glienke de Blanco, unpublished data), however, the fungus has been associated with leaf spot and minor fruit spot, respectively. Under the name $P$. capitalensis it is also known as a pathogen of orchids (36). Our experience is that minute spots on grapefruit, lemon, and lime fruits may sometimes indeed produce cultures of G. mangiferae. However, in such cases, the fungus may have been present endophytically in the peel prior to lesion formation by pathogenic Colletotrichum spp., which are nearly always present in the peel. When selecting fruits with symptoms, it is therefore inevitable that endophytic fungi that do not cause these symptoms are also isolated. Altogether, G. mangiferae proves to be a ubiquitous endophyte that has been associated with leaf spots in few host species, not including Citrus. Co-occurrence of G. citricarpa and G. mangiferae on the same host (Citrus spp.) does not indicate evolutionary convergence in host specialization in two Guignardia spp. but clearly is a matter of coincidence. Many other host species of G. mangiferae also carry other Guignardia and Phyllosticta spp. (36).

\section{ACKNOWLEDGMENTS}

This study was supported by a grant from the Ministry of Agriculture, Nature Management and Fisheries of The Netherlands (DWK-337). G. C. Carroll acknowledges the assistance of M. Wingfield, who provided support and laboratory facilities at the University of Bloemfontein, RSA, for a period of sabbatical leave in 1996-97 during which many of the isolates used for this study were collected. We thank K. Rosendahl, H. de Gruyter, J. Meffert, and E. Ilieva for technical assistance; M. Palm for forwarding specimens and cultures from USDA Customs intercepts at several U.S. ports of entry; D. Hemmes for providing material from Hawaii; and M. De Leon, M. Forvé, N. Herschberger, M. Jones, J. Martin, B. Rader, and T. Weaver who worked to determine the identity of isolates using either ITS sequences or species-specific primers.

\section{LITERATURE CITED}

1. Anonymous. 2000. EU Directive 2000/29/EC. European Union, Brussels, Belgium.

2. Benson, A. H. 1895. Black spot of the orange. Agric. Gaz. N. S. W. 6:249.

3. Brodrick, H. T., and Rabie, C. J. 1970. Light and temperature effects on symptom development and sporulation of Guignardia citricarpa Kiely, 
on Citrus sinensis (Linn) Osbeck. Phytophylactica 2:157-164.

4. Chiu, R. J. 1955. Studies on black spot of citrus. J. Agric. For. 9:1-18.

5. Doidge, E. M. 1929. Some diseases of Citrus prevalent in South Africa. S. Afr. J. Sci. 26:324.

6. Gams, W., Hoekstra, E. S., and Aptroot, A. 1988. CBS Course of Mycology, 4th ed. Centraalbureau voor Schimmelcultures, Baarn/Delft, the Netherlands.

7. Hennings, P. 1908. Fungi S. Paulenses IV a cl. Puttemans collecti. Hedwigia 48:1-20.

8. Holliday, P. 1980. Fungus Diseases of Tropical Crops. Cambridge University Press, Cambridge.

9. Kiely, T. B. 1948. Preliminary studies of Guignardia citricarpa n. sp. the ascigerous state of Phoma citricarpa McAlp. and its relation to black spot of citrus. Proc. Linn. Soc. N. S. W. 73:249-292.

10. Kiely, T. B. 1949. Black spot of citrus in New South Wales coastal orchards. Agric. Gaz. N. S. W. 60:17-20.

11. Kotzé, J. M. 1981. Epidemiology and control of citrus black spot in South Africa. Plant Dis. 65:945-950.

12. Kotzé, J. M. 2000. Black spot. Pages 23-25 in: Compendium of Citrus Diseases, 2nd ed. L. W. Timmer, S. M. Garnsey, and J. H. Graham, eds. The American Phytopathological Society, St. Paul, MN.

13. Lee, Y. S. 1969. Pathogenicity of different isolates of Guignardia citricarpa Kiely from various sources to Ponkan fruit. J. Taiwan Agric. Res. 18:45-50.

14. McAlpine, D. 1899. Fungus diseases of citrus in Australia and their treatment. Agric. Dep. Victoria, Melbourne, Australia.

15. McMillan, R. T. 1986. Guignardia citricarpa a cause of black spot on mango foliage in Florida. J. Phytopathol. 117:260-264.

16. McOnie, K. C. 1964. The latent occurrence in citrus and other hosts of a Guignardia easily confused with $G$. citricarpa, the black spot pathogen. Phytopathology 54:40-43.

17. McOnie, K. C. 1964. Source of inoculum of Guignardia citricarpa, the citrus black spot pathogen. Phytopathology 54:64-67.

18. McOnie, K. C. 1964. Orchard development and discharge of Guignardia citricarpa and the onset of infection in relation to the control of citrus black spot. Phytopathology 54:1448-1453.

19. McOnie, K. C. 1964. Apparent absence of Guignardia citricarpa Kily from localities where citrus black spot is absent. S. Afr. J. Agric. Sci. 7:347-354

20. McOnie, K. C. 1965. Does fungus pathogen of black spot disease occur in citrus in the Cape province? S. Afr. Citrus J. March:1-2.

21. McOnie, K. C. 1965. Studies on the host range of the black spot fungus. S. Afr. Citrus J. April:1-3.

22. McOnie, K. C. 1965. Source of infection for black spot of citrus. S. Afr. Citrus J. June:5-9.

23. McOnie, K. C. 1967. Germination and infection of citrus by ascospores of Guignardia citricarpa in relation to control of black spot. Phytopathology 57:743-746.

24. Meyer, L., Slippers, B., Korsten, L., Kotzé, J. M., and Wingfield, M. J. 2001. Two distinct Guignardia species associated with citrus in South Africa. S. Afr. J. Sci. 97:191-194.

25. Nei, M., and Li, W. H. 1979. Mathematical model for studying genetic variation in terms of restriction endonucleases. Proc. Natl. Acad. Sci. USA 76:5269-5273.

26. Okane, I., Nakagiri, A., and Ito, T. 2001. Identity of Guignardia sp. inhabiting ericaceous plants. Can. J. Bot. 79:101-109.

27. Pernezny, K., and Simone, G. W. 2000. Proposed list of common names of diseases on Mango (Mangifera indica L.). Phytopathol. News 34:2526

28. Rayner, R. W. 1970. A Mycological Colour Chart. Commonw. Mycol. Inst., Kew, England.

29. Roy, A. J. 1968. Some fungi from Almora. Indian Phytopathol. 20:340348.

30. Schüepp, H. 1961. Untersuchungen über Guignardia citricarpa Kiely, den Erreger der Scwarzfleckenkrankheit auf Citrus. Phytopathol. Z. 40: 258-271.

31. Schutte, G. C. 1995. Evaluation of control strategies for citrus black spot in southern Africa. Ph.D. thesis. University of Pretoria, South Africa.

32. Smith, I. M., McNamara, D. G., Scott, P. R., Holderness, M., and Burger, B. 1997. Quarantine Pests for Europe, 2nd ed. Data sheets on quarantine pests for the European Union and for the European and Mediterranean Plant Protection Organization. CAB International, Wallingford, U.K.

33. Snowdon, A. L. 1990. A colour atlas of post-harvest diseases and disorders of fruits and vegetables. Pages 62-63 in: General Introduction and Fruits. Wolfe Scientific Ltd., London, U.K.

34. Sutton, B. C., and Waterston, J. M. 1966. Guignardia citricarpa. No. 85 in: CMI Descriptions of Plant Pathogenic Fungi and Bacteria. CAB International, Wallingford, U.K.

35. Van de Peer, Y., and De Wachter, R. 1994. Treecon for Windows: A software package for the construction and drawing of evolutionary trees for the Microsoft Windows environment. Comput. Appl. Biosci. 10:569-570.

36. Van der Aa, H. A. 1973. Studies in Phyllosticta. Stud. Mycol. 5:1-110.

37. Von Arx, J. A., and Müller, E. 1954. Die Gattungen der Amerosporen Pyrenomyceten. Beitr. zur Kryptogamenflora Schweiz Band 11, Heft 1. Büchler \& Co., Bern, Switzerland.

38. Wager, V. A. 1952. Black spot disease of citrus in South Africa. Sci. Bull. Dep. Agric. S. Afr. No. 303.

39. Wang, C. K., and Tsai, Y. P. 1974. Cultural and morphological comparison of Phoma citricarpa and P. citricarpa var. mikan in imperfect and perfect stages. Plant Prot. Bull. (Taiwan) 16:141-152.

40. Werres, S., Marwitz, R., Man in't Veld, W. A., De Cock, A. W. A. M., Bonants, P. J. M., De Weerdt, M., Themann, K., Ilieva, E., and Baayen, R. P. 2001. Phytophthora ramorum sp. nov., a new pathogen on Rhododendron and Viburnum. Mycol. Res. 105:1155-1164.

41. White, T. J., Bruns, T., Lee, S., and Taylor, J. W. 1990. Amplification and direct sequencing of fungal ribosomal RNA genes for phylogenetics. Pages 315-322 in: PCR Protocols: A Guide to Methods and Applications. M. A. Innis, D. H. Gelfand, J. J. Sninsky, and T. J. White, eds. Academic Press, San Diego.

42. Winton, L. M., Stone, J. K., Watrud, L. S., and Hansen, E. M. 2002. Simultaneous one-tube quantification of host and pathogen DNA with real-time polymerase chain reaction. Phytopathology 92:112-116.

43. Yip, H. Y. 1989. Five new species of Phyllosticta on Australian native plants. Mycol. Res. 93:489-496. 